\title{
Enhanced oil removal from a real polymer production plant by cellulose nanocrystals - Serine incorporated polyethersulfone ultrafiltration membrane
}

\author{
Azar Asadi ( $\sim$ azarasadi_88@yahoo.com ) \\ Yasouj University Gachsaran Oil and Gas Faculty https://orcid.org/0000-0002-1684-3032 \\ Foad Gholami \\ Razi University of Kermanshah: Razi University \\ Ali Akbar Zinatizadeh \\ Razi University of Kermanshah: Razi University
}

\section{Research Article}

Keywords: Ultrafiltration, cellulose nanocrystals, oily wastewater, long-term performance

Posted Date: August 16th, 2021

DOl: https://doi.org/10.21203/rs.3.rs-793711/v1

License: (c) (1) This work is licensed under a Creative Commons Attribution 4.0 International License.

Read Full License 


\section{Enhanced oil removal from a real polymer production plant by cellulose nanocrystals - Serine incorporated polyethersulfone ultrafiltration membrane}

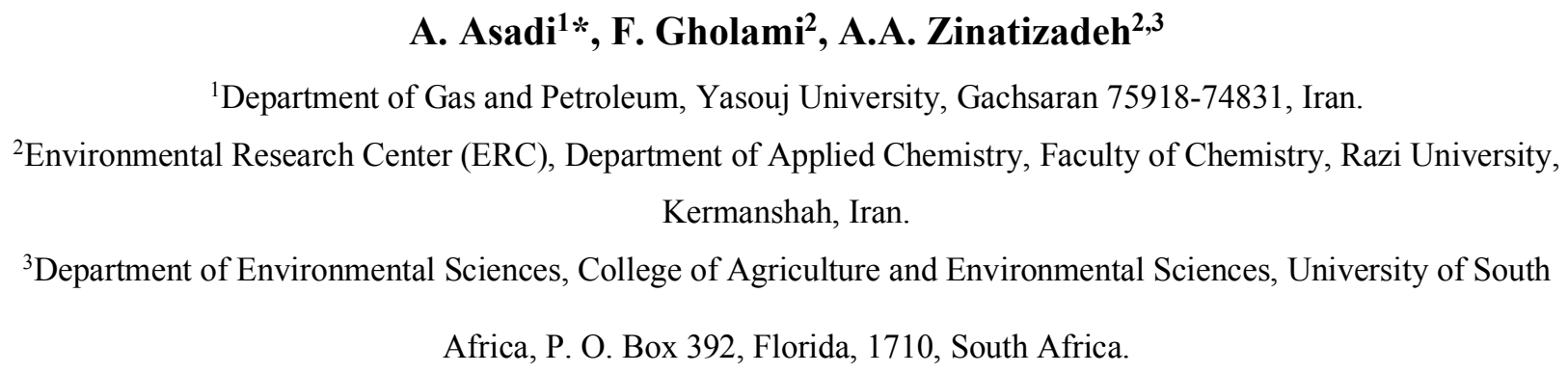

\section{Abstract:}

As discharging oily wastewater from industries to the environment is a potential threat for the aquatic ecosystem, in this research oil removal from a real case of Kermanshah polymer production plant wastewater was investigated. The focus of this study was on improving the oil rejection performance of polyethersulfone (PES) ultrafiltration membrane due to adding cellulose nanocrystals (CNC) and modified CNC with Serine amino acid (CNC-Ser) in PES mix matrix. From the results, the membranes embedded with CNC-Ser showed better performance in terms of water flux, flux recovery ratio and oil rejection (higher than 97\%) compared to the modified membranes with CNC. The lowest water contact angle (41.370), the smoother surface and higher negative surface potential (-24 mv) was achieved for the optimum loading of CNC-Ser. Besides, long-term performance of the membranes with optimum loading of CNC and CNC-Ser were compared in both dead-end and cross-flow set-ups.

\section{Keywords: Ultrafiltration, cellulose nanocrystals, oily wastewater, long-term performance.}

6

7


Introduction:

33 With developing industrialization, the treatment of industrial wastewater has become a main concern in all over the world [1]. The treatment and disposal of oily wastewaters is a major challenge for some industries like petrochemical, food, and pharmaceutical. Petrochemical industry inevitably generates large volumes of oily wastewater over the chemical process for instance the production of high density polyethylene as a byproduct [2, 3]. Therefore, petrochemical industry must separate oil from wastewater before releasing wastewater to environment. Also these days' seawater is being polluted by oil leakage and discharging effluents [4]. Various technology has been applied for treating oily wastewaters i.e. air flotation [5], ultrasonic irradiation [6], bioremediation [7], microwave irradiation [8] and pyrolysis [9]. It has been proved that the mentioned methods are not qualified enough as a result of their disadvantaged like being costly, inefficient in low oil concentration $(\leq 100 \mathrm{ppm})$ and generate second pollutions in some cases [10-12].

Membrane technology has been noticed by over recent decades resulted from its impressive separation even in low ranges of oil concentration, however, fouling phenomenon and needing to be cleaned frequently is a restriction for membrane technology [13-15]. Ultrafiltration has been used frequently for oil separation from oily wastewaters. In order to reduce the fouling phenomenon and increase the performance of ultrafiltration the polymeric membranes have been modified by different additives and fillers to obtain more hydrophilic membranes e.g., $\mathrm{TiO}_{2}$ [16], carbon Nanotubes (CNT) [17], covalent organic framework (COF) [18], mesoporous [19], $\mathrm{C}_{3} \mathrm{~N}_{4}$

[20], metal-organic framework (MOF) [21], and cellulose nanocrystals [22].

In 2019, Liu et al. reported mesoporous hybrid $\mathrm{PAV} / \mathrm{SiO}_{2}$ nanoparticle in PVDF membrane for simultaneous oil and heavy metals rejection. From the reported results, an acceptable heavy metal rejection beside of adequate anti-fouling ability and high water flux have been observed [19]. Gholami and coworkers studied anti-fouling property and oily wastewater rejection by adding $\mathrm{Zn}$ based MOF (TMU-5) to PES polymer membrane [21]. Due to hydrophilic nature of nanoparticles in membrane matrix, excellent hydrophilic and anti-fouling properties have been achieved. [21]. In another study, Lee et al. applied direct osmosis TFC membrane including poly [3-(N-2methacryloylxyethyl-N, N-dimethyl)-ammonatopropanesulfonate] (PMAPS) for oil rejection from oily wastewater which high flux and low-fouling phenomenon, and 95\% removal efficiency for oil emulation has been reported [23]. Also, Zarghami and others used polymerization of 
dopamine on PES membrane which dopamine improved the water flux with good self-cleaning and anti-fouling properties (efficiency above 98\%) [24]. Besides, $\mathrm{ZnO}$ microsphere/carbon nanotube as a filler in PES membrane has been also showed high rejecting, good flux and longterm stabling [25]. In another research, ZNG-g-PVDF based membrane has been exhibited high anti-fouling quality and high oil rejection for very low concentration of oil pollution (13 ppm) [26].

The application of nano-biomaterials as filler in polymer matrix has been noticed by researchers because of their favorite features like being cost-effective, biocompatible and nontoxic. Cellulose nanocrystals (CNCs) as renewable nano-scaled biomaterials have been applied in different researches to enhance and modify polymer characteristics due to its high hydrophilicity, good dispersion in water and polar solvents. Besides, the hydrophilic characteristics of CNC could be improved by conjugating with hydrophilic groups such as amino acids. Hence, amino acid with $\mathrm{COOH}$ and $-\mathrm{NH}_{2}$ groups provides superior hydrophilic nano-biomaterial compared to $\mathrm{CNC}$ alone, which has only -COOH group [27, 28].

From the literature, there are no any reports about using cellulose nanocrystals (CNC) modified with serine amino acids to improve hydrophilicity of PES membranes. CNC are derived from cellulose showed high surface area which have been applied for absorption and catalyst field. In spite of high stability and hydrophilicity of CNC, they have not been used broadly to improve the features of membranes for wastewater treatment. As a notice, it can be used to construct a novel membrane by the phase inversion method. In the current study, a nanocomposite UF membrane based on PES and CNC modified with serine amino acid including- $\mathrm{NH}_{2}$ and $-\mathrm{COOH}$ functional groups is prepared via a phase inversion technique for purification of oily wastewaters. The CNCSerine is firstly synthesized and characterized, and then embedded into the PES membrane. In order to identify membrane characteristics, contact angle, SEM, AFM, zeta potential and antifouling tests are used. It should be mentioned that the optimal membranes have been used to reject oil from Kermanshah polymer production plant wastewater.

\section{Material and methods}

\subsection{Materials}

Polyethersulfone (PES) (MW= 58000 g.mol-1, ultrason E6020P) and dimethylacetamide (DMAc) as a solvent were purchased from BASF (Germany). Polyvinylpyrrolidone (PVP) (MW=25000 g 


21

22

mol-1), and ethanol were purchased from Merck (Germany). All chemicals were used without further purification. The used milk powder was provided by commercial source (GUIGOZ Growth 3 Formula Milk Powder from 1 year to 3 years), and diesel oil was obtained from Oil Castrol Magnatec (10W-40). For membrane drying step, several filter papers of Whatman (1001-734 Grade 1, size: $46 \mathrm{cmX100m)} \mathrm{were} \mathrm{used.}$

\subsection{CNC modification}

Serine and the carboxyl groups of $\mathrm{CNC}$ were counjugated by 1-Ethyl-3-(3-dimethylaminopropyl) carbodiimide (EDC)/ N-hydroxysuccinimide (NHS) coupling to synthesis amine functionalized CNC. Dried CNC was dispersed in ethanol by sonication for $45 \mathrm{~min}$. EDC (54.3 mg, $0.4 \mathrm{mmol})$ and NHS (50.6 mg, $0.4 \mathrm{mmol})$ were added to the $\mathrm{CNC}$ solution $\left(0.5 \mathrm{~g} \cdot \mathrm{ml}^{-1}, 0.5 \mathrm{~g}\right)$. Then, the serine was added to the $\mathrm{CNC}$ solution and stirred for 1 day at room temperature. The resulting CNC-Ser solution was centrifuged and washed in ethanol to remove unreacted serine [29].

\subsection{Preparation of mixed matrix membrane}

Phase inversion method has been applied for preparing Flat-sheet symmetric porous membranes modified with $\mathrm{CNC}$ based additives. The composition of the used different mixed solutions is shown in Table 1. An appropriate amount of additive was mixed with DMAc and sonicated (DT $102 \mathrm{H}$ bandeling ultrasoni, Germany) for $25 \mathrm{~min}$. Then, PVP and PES were added to the solution and mixed for $24 \mathrm{~h}$ (400 rpm). After obtaining homogeneous casting solution a film applicator and several neat glassy plates were utilized to fabricate membranes with thickness of $150 \mu \mathrm{m}$ thickness. In next step, whole glass was immersed into distilled water (room temperature) to form the solid polymeric membranes. Then, the flat -sheet membranes were immersed into fresh distilled water for $24 \mathrm{~h}$. In order to dry the obtained membranes, they were kept between two filter papers for another $24 \mathrm{~h} \mathrm{[30]}$. 
Table 1. The casting solution composition for membrane preparation.

\begin{tabular}{ccccc}
\hline Membrane type & PES (wt.\%) & PVP (wt.\%) & DMAc (wt.\%) & CNC-Ser (wt.\%) \\
\hline M1 & 18 & 1 & 81.0 & - \\
M2 & 18 & 1 & 80.9 & $0.1^{\mathrm{a}}$ \\
M3 & 18 & 1 & 80.5 & $0.5^{\mathrm{a}}$ \\
M4 & 18 & 1 & 80.0 & $1.0^{\mathrm{a}}$ \\
M5 & 18 & 1 & 80.9 & $0.1^{\mathrm{b}}$ \\
M6 & 18 & 1 & 80.5 & $0.5^{\mathrm{b}}$ \\
M7 & 18 & 1 & 80.0 & $1.0^{\mathrm{b}}$ \\
\hline
\end{tabular}

a) $\mathrm{CNC}$, b) CNC-Ser

125

126

127

128

129

130

131

132

133

134

135

136

137

138

139

140

141

142

143

144

145

146

\subsection{Characterization of CNC-based membrane morphology}

Scanning electron microscope (SEM, Philips-XL30, The Netherland) was applied with acceleration voltage of $20 \mathrm{kV}$. Small sample of membrane was frozen by liquid nitrogen and dried, then by sputtering, a thin layer of gold was coated on the membrane surface to make conduction. Atomic force microscopy (AFM) was used to study the surface of the prepared membranes. In this method specific area of the membrane sample $(2 \times 2 \mathrm{~cm})$ was fixed on specimen holder, then a highresolution microscope (Nanosurf $\AA$ Mobile $\mathrm{S}$ scanning probe-optical microscope, Switzerland) physically scanned the level, three dimensionally $(4 \times 4 \mu \mathrm{m})$. The difference between peaks and valleys defined as surface roughness. Smoother surface has less difference in these parameters. The AFM images can be observed as Sa (average roughness), Sq (root of two data), and Sz (the average data between lowest valley and highest peak). The membrane water tendency was quantified by water contact angle (WCA) measurement. Less contact angle between membrane surface and water droplet indicates more hydrophilic nature. For this purpose, on the proper size of clean membrane, a small droplet of distilled water was injected $(4 \mu \mathrm{L})$. After waiting for 10 seconds, to face with stable conditions, a digital microscope (Contact Anglemeter XCA-50) was captured the cross sectional images and the WCAs were calculated. More importantly to make the obtained results more reliable, 5 random places on the membrane surface were measured and average data was reported. 


\subsection{Porosity measurement of the prepared membranes}

148 The membrane porosity was calculated based on gravimetric method. At first, $4 \mathrm{~cm} 2 \mathrm{of}$ all membranes was cut and weighted precisely, then submerged into distilled water for $24 \mathrm{~h}$ and finally

150 it was weighted again. Based on equation 1, the membrane porosity was calculated:

$$
\varepsilon=\frac{\omega_{1}-\omega_{2}}{\mathrm{~A} \times \mathrm{L} \times \mathrm{dW}}
$$

151 Which $\omega_{-} 1$ and $\omega \_2$ are the wet and dry weight of membranes. A, L, and dW are effective surface, 152 membrane thickness and water density $(998 \mathrm{~kg} / \mathrm{m} 3)$, respectively.

153 Besides, mean pore radius (rm) was calculated according to Guerout-Elford-Ferry equation (2):

$$
r_{m}=\sqrt{\frac{(2.9-1.75 \varepsilon) \times 8 \eta l Q}{\varepsilon \times A \times \Delta P}}
$$

154 Where, $\eta$ is the water viscosity $(8.9 \times 10-4 \mathrm{~Pa} \mathrm{~s}), \mathrm{Q}$ is the volume of the permeate pure water per 155 unit time $(\mathrm{m} 3 / \mathrm{s})$, and $\Delta \mathrm{P}$ is the operating pressure $(0.5 \mathrm{M} \mathrm{Pa})[31]$.

156 The surface free energy $(\Delta \mathrm{Gs})$ of the membranes was calculated using the Young Dupre equation 157 (Equation 3) [32].

$$
-\Delta G_{S}=(1+\cos \theta) \gamma_{L}
$$

where $\theta$ is the water contact angle value and $\gamma \mathrm{L}$ is the surface tension of water $(72.8 \mathrm{~mJ} / \mathrm{m} 2)$.

\subsection{Membrane setup and performance}

161 A stainless steel dead-end setup with volume capacity of $150 \mathrm{ml}$ and effective membrane surface 162 of $12.56 \mathrm{~cm} 2$ was applied to evaluate membrane performance. The applied driving force to pass 163 feed solution through the dead- end setup was the pressure of nitrogen gas (3 bar).

164 Also, to reduce feed polarization a stirrer was provided in setup. The weights of obtained samples 165 passed through setup was determined by a digital balance and the pure water flux (PWF) was

166 calculated based on equation 4:

$$
J_{w .1}=\frac{M}{A \Delta t}
$$

167 Where $\mathrm{M}, \mathrm{A}, \Delta \mathrm{T}$ are permeating weight $(\mathrm{kg})$, effective membrane area $(\mathrm{m} 2)$, and filtration time 168 (h), respectively [33]. 
Also, the long term performance of the optimum membranes in a cross-flow set- up with volumetric flow rate of $250 \mathrm{l} / \mathrm{min}$ and operating pressure of 3 bar was evaluated

\subsection{Fouling effect}

Resistance of the membranes was examined by passing milk powder solution (1000 ppm) through dead-end set up as fouling agent. At first, distilled water was passed through dead-end set up (60 min, 3 bar), in the second step, milk powder solution was filtered for $90 \mathrm{~min}$, then the membrane was washed and immersed into distilled water (20 min), and finally, the distilled water was filtered again (60 $\mathrm{min})$. After all, flux recovery ratio (FRR) and the membrane resistance are calculated according to equation 5 which FRR was considered as membrane resistivity against fouling:

$$
F R R=\left(\frac{J w 2}{J w 1}\right) \times 100
$$

Where, JW1 and JW2 were PWF of the first step and second step, respectively. Different types of fouling including: total fouling ratio $(\mathrm{Rt})$, reversible fouling ratio $(\mathrm{Rr})$, and irreversible fouling ratio (Rir) were also calculated:

$$
\begin{aligned}
& R_{t}(\%)=\left(1-\frac{j_{p}}{j_{w .1}}\right) \times 100 \\
& R_{r}(\%)=\left(\frac{j_{w .2}-j_{p}}{j_{w .1}}\right) \times 100 \\
& R_{i r}(\%)=\left(\frac{j_{w .1}-j_{w .2}}{j_{w .1}}\right) \times 100=R_{t}-R_{r}
\end{aligned}
$$

\subsection{Oil rejection and characteristics of Kermanshah polymer production plant wastewater}

The simulated oily wastewater with 100, 300 and 500 ppm was utilized to investigate rejection performance and finally the long performance of the optimum membrane in removing oil from a real petroleum wastewater was examined in both dead-end and cross-flow set-up. In dead-end setup, oil-water emulsion (diesel oil, SAF 40) has been provided by heating up the mixture at $50{ }^{\circ} \mathrm{C}$ and stirring $(400 \mathrm{rpm})$ for $100 \mathrm{~min}$ without emulsifier. Also, with applying stirrer and sonication the oil droplet size distribution was kept constant.

Also, Kermanshah polymer production plant wastewater, Kermanshah, Iran, as a real oily wastewater is used to evaluate the membrane performance in this study. The characteristics of the 
191 polymer production plant wastewater are as follow: COD of $500 \mathrm{mg} / 1$, TSS of $395 \mathrm{mg} / 1$, and $\mathrm{pH}$ 192 of 5.5-7.

\section{3. Results and discussion}

\section{3.1. Characterization of CNC and CNC-Ser}

196 For ensure to take place surface modification on CNC, FT-IR, SEM and zeta potential tests were 197 performed. Figs $1 \mathrm{a}$ and $\mathrm{b}$ show FT-IR spectra for CNC and CNC-Ser, respectively. Also, he 198 functional groups related to the observed bands have been specified. Based on the figs, the bands of NH2 (around $3500 \mathrm{~cm}-1$ ), NH and COOH (around $1600 \mathrm{~cm}-1$ ) were appeared in the FT-IR 200 spectrum of CNC-Ser, however, they are not observed in the spectrum of CNC. This outcome is a 201 firm evidence to modify CNC by serine [34, 35].

202 SEM images of CNC and CNC-Ser were illustrated in Figs 2a and b, respectively. From SEM 203 images, the differences between the surface of CNC and CNC-Ser are obviously found out. The 204 Figs showed that the surface of CNC was rougher rather than CNC-Seri. It should be noted that 205 the surface of CNC was become slicker by inserting Serine amino acid on its surface [36].

206 Besides, zeta potential of CNC and CNC-Ser was assessed as another evidence for surface 207 modification which are shown in Figs 3a and b. Based on the Figs, the location of zeta potential 208 peak and also the intensity of zeta potential peak were varied with surface modification of CNC. 209 It is observed that zeta potential peak was shifted from $-25 \mathrm{mv}$ for CNC to $-50 \mathrm{mv}$ for CNC-Ser 210 and also the intensity of zeta potential peak was altered from 4000 total counts for CNC to 6000 211 total counts for CNC-Ser [37].

212 


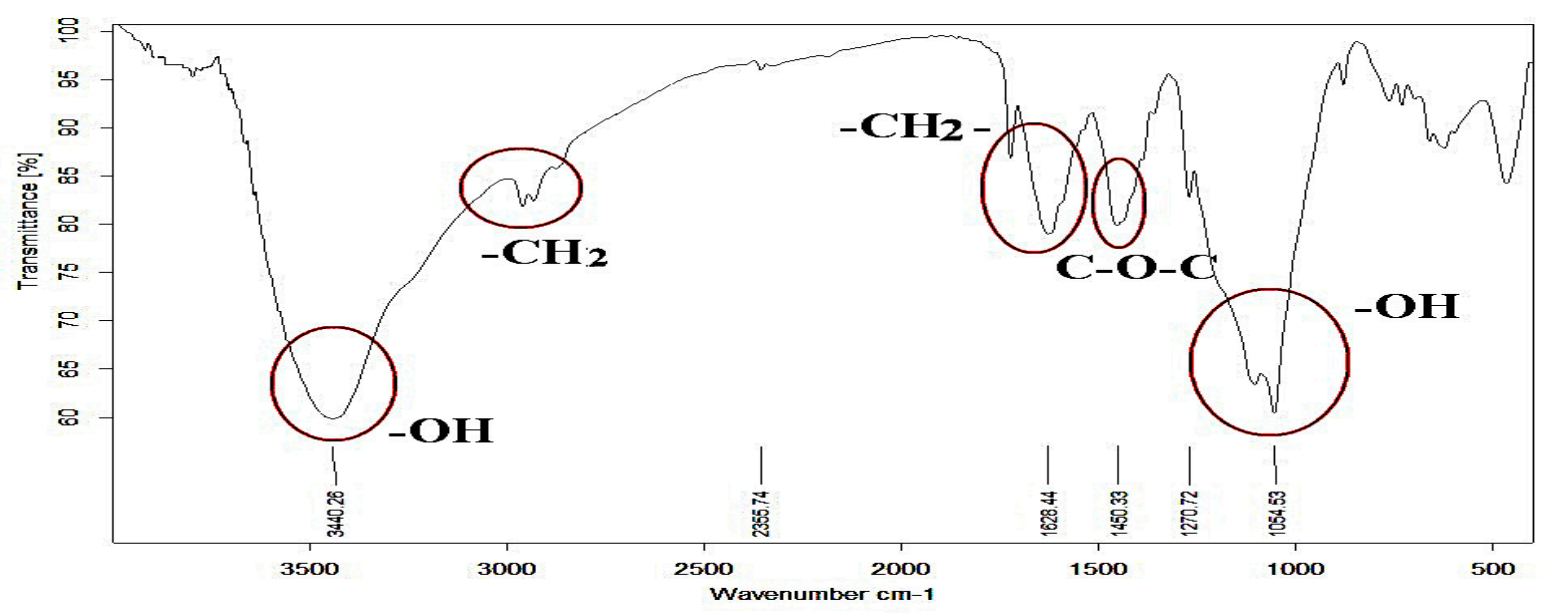

(a)

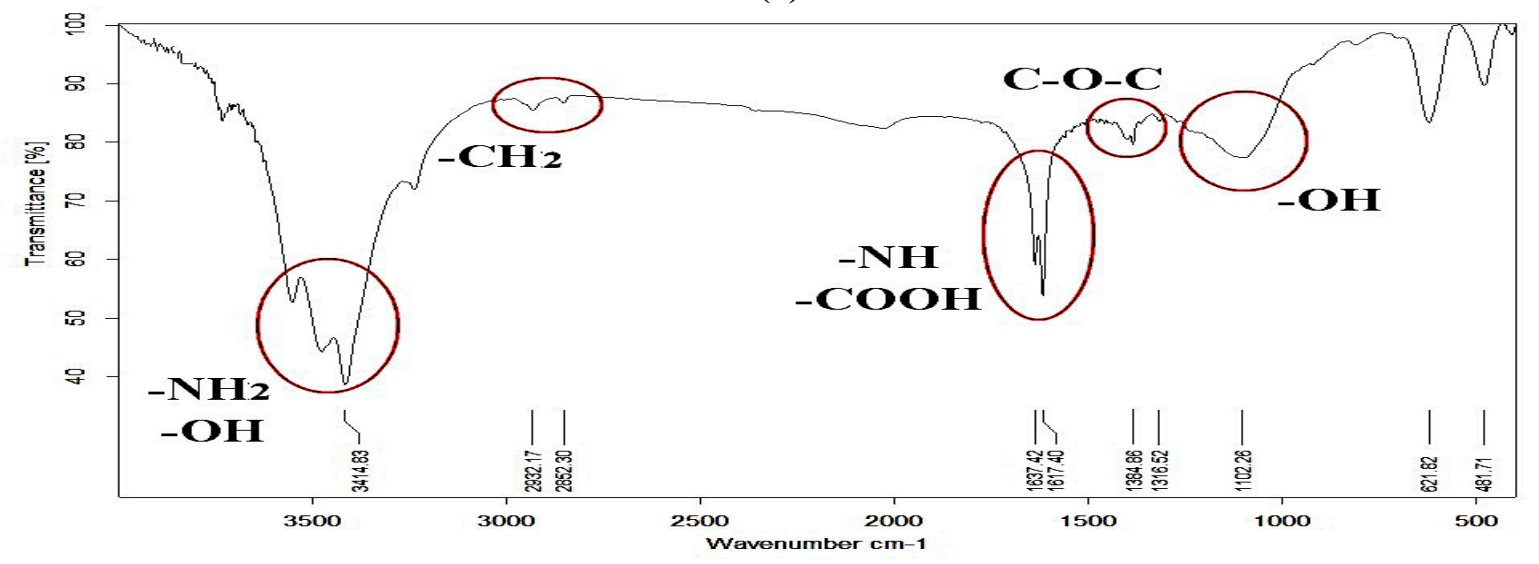

(b)

Fig. 1. FT-IR spectra of CNC (a) and CNC-Ser (b).

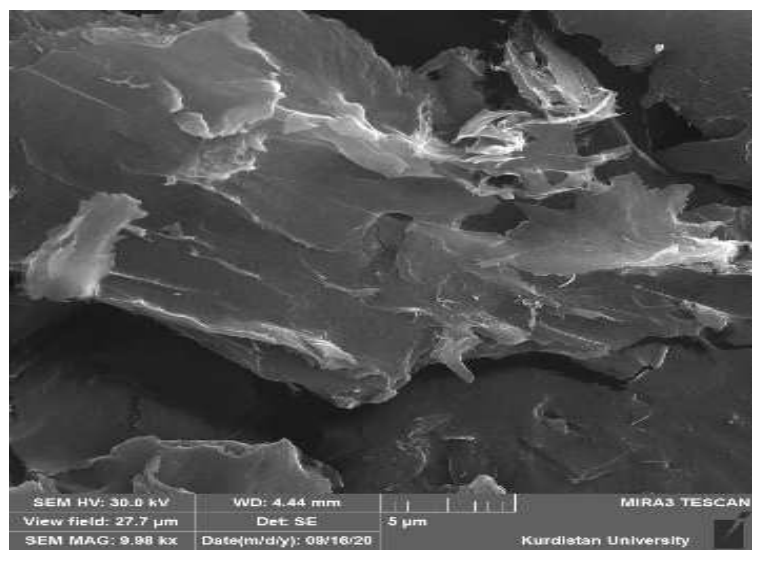

(a)

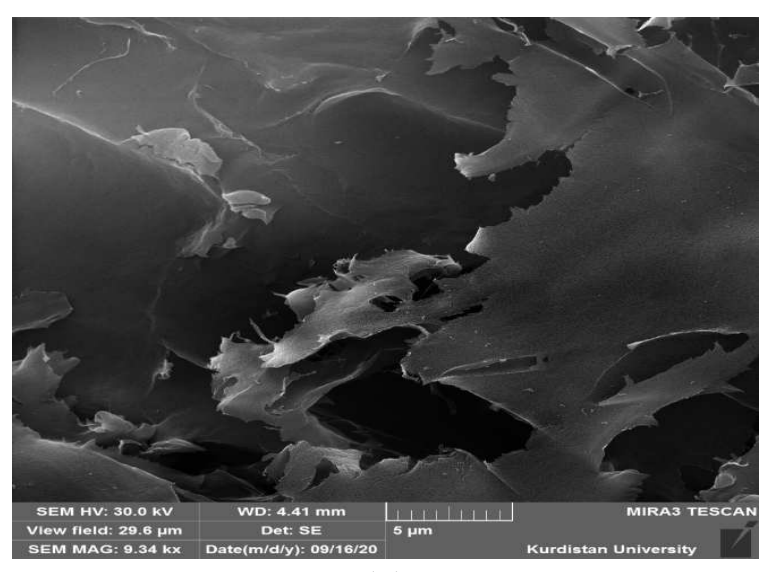

(b)

Fig.2. SEM images for CNC (a) CNC-Ser (b) 


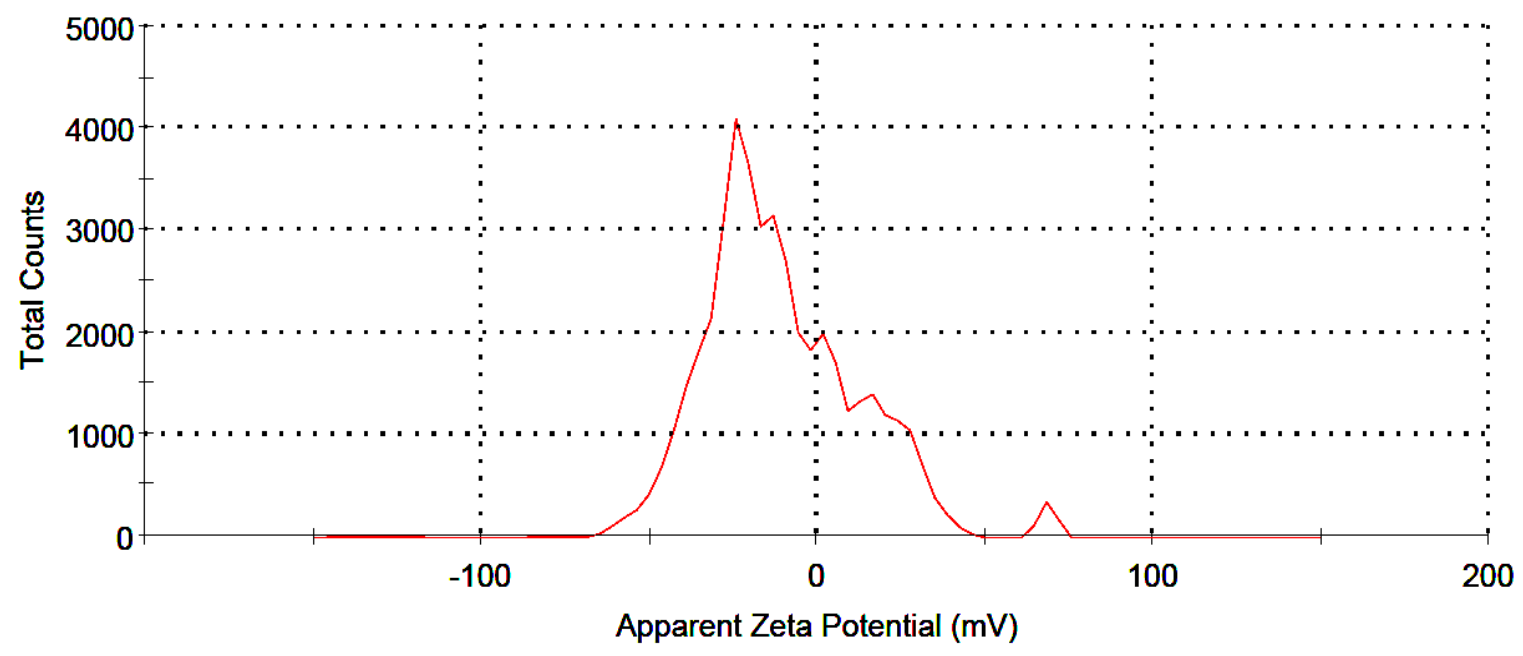

(a)

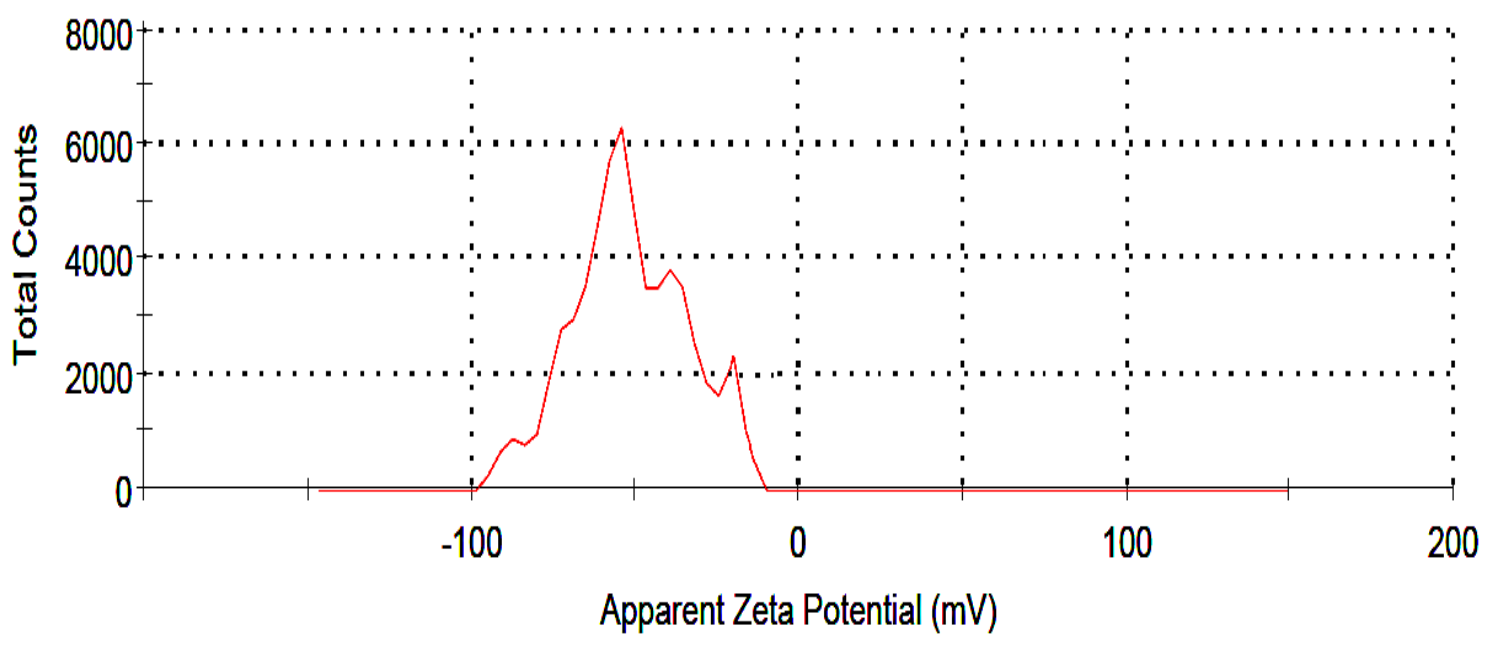

(b)

Fig.3. Zeta potential of CNC (a) and CNC-Ser (b)

\subsection{Membrane hydrophilicity}

216 It is accepted that the presence of hydrophilic additives in membrane matrix caused a reduction in

217 water contact angle (WCA) due to enhancing in membrane hydrophilicity. According to WCA 218 results presented in Table 2, WCA of the bare membrane (M1) was decreased with addition of 219 CNC and CNC-Se (M2-M7), verifying the effect of hydrophilic groups. In overall, the membranes 220 embedded with CNC-Ser (M5-M7) showed lower WAC relative to the membranes embedded with $221 \mathrm{CNC}(\mathrm{M} 2-\mathrm{M} 5)$. This outcome is another prof for inserting Serine amino acid with NH2 and COOH 
222 groups on the surface of $\mathrm{CNC}$ which makes the surface more hydrophile. The lowest value of 223 WCA was reported for the lowest loading of CNC-Ser (M5 with 0.1\%) as a result of the proper 224 dispersion of the additive into the polymeric matrix. The WAC for the lowest loading of CNC and $225 \mathrm{CNC}-\mathrm{Ser}$ was found to be $41.37^{\circ}$ and $63.52^{\circ}$ for M5 and M2, respectively, which this difference 226 is a sign of the presence of hydrophilic functional groups of serine. It should be mention that an 227 increase in the CNC-Ser loading (0.5, and $1.0 \mathrm{wt} . \%)$ resulted an increase in WCA and a reduction 228 in the hydrophilicity of the membranes which could be explained by an increasing trend of the 229 viscosity casting solution in higher loading of CNC-Ser. Moreover, the aggregation of nanostructures in higher loading could be another reason for decreasing homogeneity and 231 increasing WCA besides the viscosity increscent [38].

232 In contrast to CNC-Ser, a decreasing trend of WCA is continued with increasing loading of CNC from $0.1-1 \%$. Pure water flux (PWF) is another parameter to assess the presence of hydrophilic additives and porosity. According to presented data for PWF in Table 2, the membranes with CNCSer represented higher values of porosity and PWF for the membrane embedded with CNC-Ser $\left(\mathrm{M} 5,91.56 \mathrm{~kg} / \mathrm{m}^{2} . \mathrm{h}\right)$ compared to the membrane with incorporated CNC (M3, $\left.70.42 \mathrm{~kg} / \mathrm{m}^{2} . \mathrm{h}\right)$. High hydrophilicity of M5 creates strong electrostatic interactions (e.g., hydrogen bonding) between the membrane surface functional groups $(-\mathrm{COOH}$ and $-\mathrm{NH} 2)$ and water molecules caused the formation of a hydration layer on the surface of the membranes and also the channel walls in the membrane matrix (based on the Hagen-Poiseuille Flow equation). It should be notice that for both series of membranes with incorporated $\mathrm{CNC}$ and $\mathrm{CNC}-\mathrm{Ser}$, at higher loadings of additives agglomeration restricted porosity and PWF compared to lower loading of additives. As an exception, PWF and porosity was not significantly decreased with increasing CNC loading

244 from 0.1 to $0.5 \%$ as a result of the loaded porous nanoparticles, however, a reduction in PWF was 245 observed from M5 (0.1\%) to M6 (0.5\%) (with CNC-Ser) due to occupying membrane pours and channels by serine functional groups. 
Table 2. Surface parameter of the prepared membranes.

\begin{tabular}{|c|c|c|c|c|c|}
\hline $\begin{array}{l}\text { Membrane } \\
\text { type }\end{array}$ & $\begin{array}{c}\text { Porosity, } \\
\%\end{array}$ & $\begin{array}{c}\text { Mean } \\
\text { radius, } \mathbf{n m}\end{array}$ & $\begin{array}{c}\text { WCA, } \\
\text { o }\end{array}$ & $\begin{array}{c}\text { Surface free } \\
\text { energy, } \mathbf{m J} / \mathbf{m}^{2}\end{array}$ & $\begin{array}{c}\text { PWF, } \\
\mathrm{kg} / \mathrm{m}^{2} . \mathrm{h}\end{array}$ \\
\hline M1 & 47.45 & 9.26 & 78.65 & 87.13 & 33.38 \\
\hline M2 & 76.54 & 8.91 & 63.52 & 105.26 & 66.02 \\
\hline M3 & 79.42 & 8.88 & 59.03 & 110.26 & 70.42 \\
\hline M4 & 65.71 & 8.81 & 57.72 & 111.68 & 49.39 \\
\hline M5 & 88.23 & 9.11 & 41.37 & 127.43 & 91.56 \\
\hline M6 & 82.65 & 8.70 & 44.3 & 124.90 & 72.98 \\
\hline M7 & 72.31 & 8.93 & 46.25 & 123.14 & 59.92 \\
\hline
\end{tabular}

256 3.3. Morphology analysis

257 Also, the tissue of the membranes was assessed by SEM cross-section analysis. According to Fig.

2584 (SEM images), a dense top-layer for the modified membranes with higher loading of additives

259 was notable. This is related to the viscosity of the casting solution that reduced the additives 260 migration speed toward membrane surface during the phase inversion. As a report, the viscosity 261 of the bare casting solution was increased from 366 (M1) to 412 for M5 and 489 for M7, indicating 262 higher viscosity in higher loading of additives. It should be mentioned that top layer of the 263 membranes at lower loading (M3 and M5) was more porous rather than the others (M4 and M7), 264 causing an improvement in passing water through the membrane channels. Overall, the data of 265 porosity were asserted by SEM cross-section images of the membranes. From Fig. 4, the presence 266 of additives ( $\mathrm{CNC}$ and $\mathrm{CNC}-\mathrm{Ser}$ ) creates obvious changes in the tissue of the membranes 267 particularly at higher loading of additives resulted in more texture deformation (M4 and M7) [39]. 


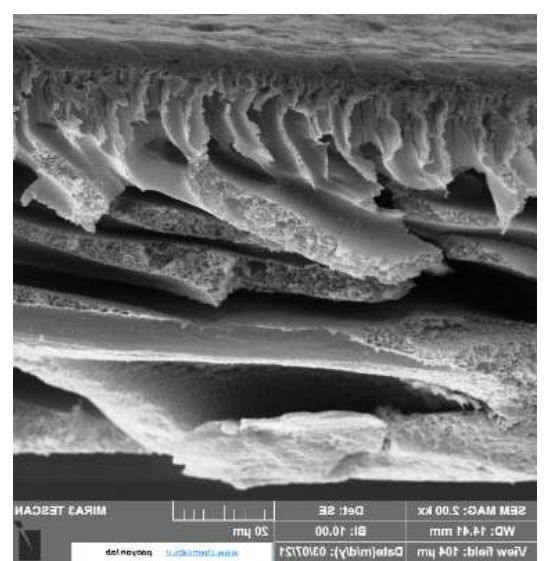

(a)

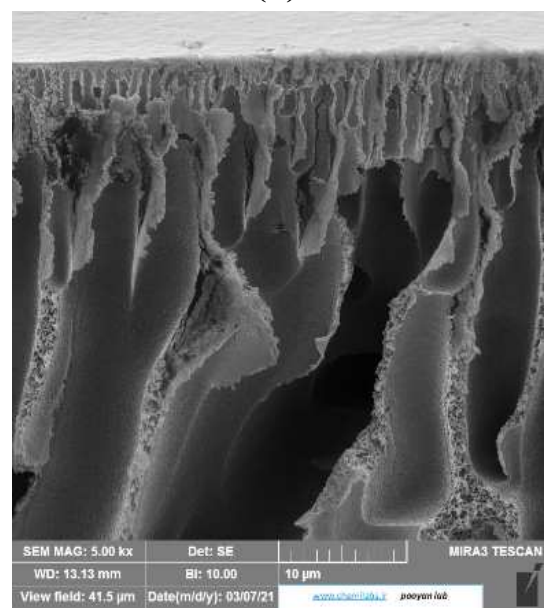

(d)

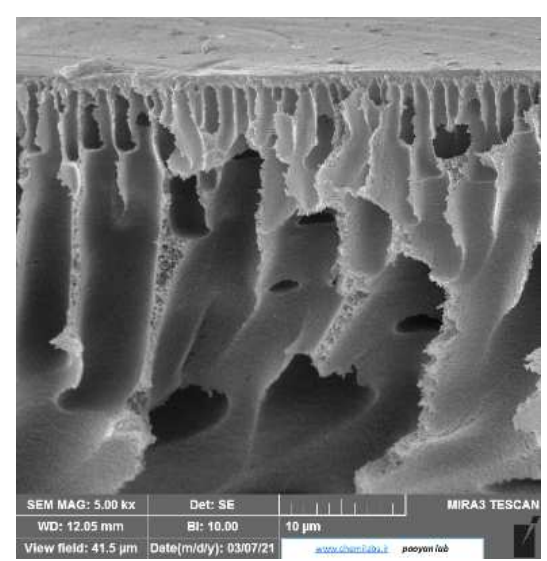

(b)

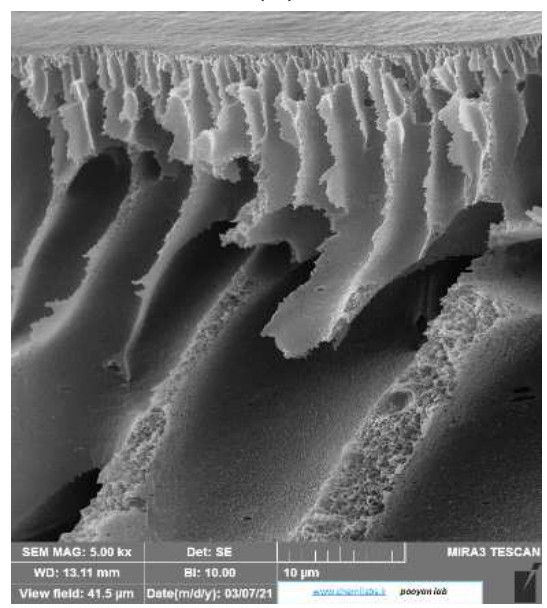

(e)

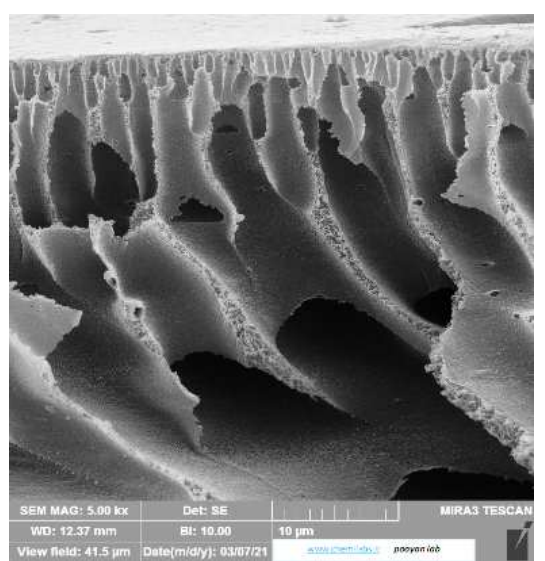

(c)

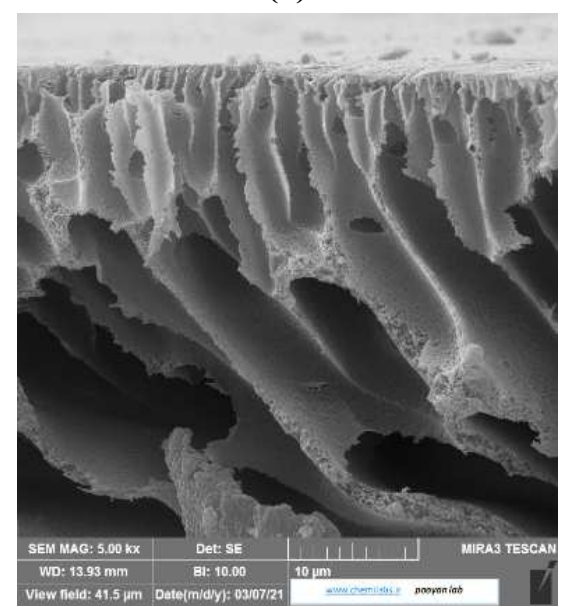

(f)

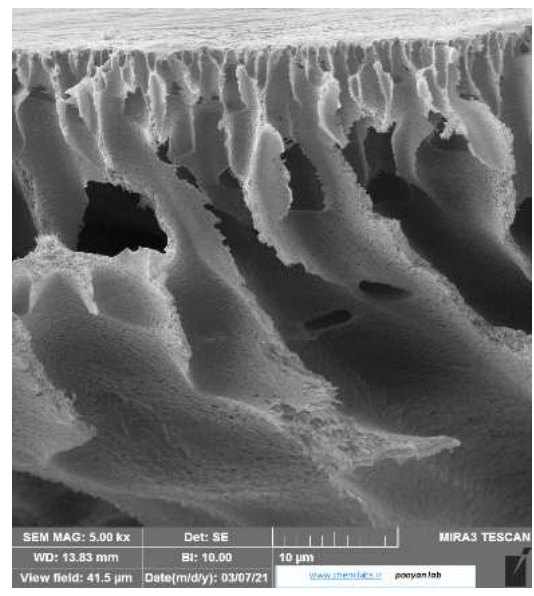

(g)

Fig. 4. SEM images of the fabricated membranes. $\mathrm{M}_{1}$ : bare membrane (a), $\mathrm{M}_{2}: 0.1 \mathrm{wt} \% \mathrm{CNC}(\mathrm{b})$, $\mathrm{M}_{3}: 0.5 \mathrm{CNC}$ (c), $\mathrm{M}_{4}: 1 \mathrm{wt} \% \mathrm{CNC}$ (d), M5: 0.1wt \% CNC-Ser (e), M6: 0.5wt\% CNC-Ser (f), M7: $1 \mathrm{wt} \% \mathrm{CNC}-\mathrm{Ser}(\mathrm{g})$. 
270 Besides, to evaluate the roughness of the surface, AFM images of the bare and modified 271 membranes are represented in Fig.5. The surface topography of the membrane's surface was 272 investigated by mean roughness $(\mathrm{Sa})$, root mean square of the $\mathrm{Z}$ data $(\mathrm{Sq})$, and the difference 273 between highest and lowest valleys (Sz) which were presented in Table 3. According to the Table, 274 the values of $\mathrm{Sa}, \mathrm{Sq}, \mathrm{Sz}$ for modified membranes were lower than the bare membrane, indicating 275 more smooth surface of the modified membranes. This result proved the presence of hydrophilic 276 additives which enhanced the surface smoothness. M3 and M5 showed the least roughness for 277 both membrane series with CNC and CNC-Ser, respectively, as a result of their good dispersions 278 of additives in the polymeric matrix creating smoother surface with less wrinkled, while, the 279 surface roughness increased at higher additive loading. Less roughness of M5 $(\mathrm{Sa}=2.44 \mathrm{~nm})$, 280 compared to $\mathrm{M} 3(\mathrm{Sa}=2.99 \mathrm{~nm})$ could be explained by more interactions between functional 281 groups of CNC-Ser $(\mathrm{NH} 2$ and $\mathrm{COOH})$ with the matrix of PES membrane exclusively over the 282 phase inversion [23].

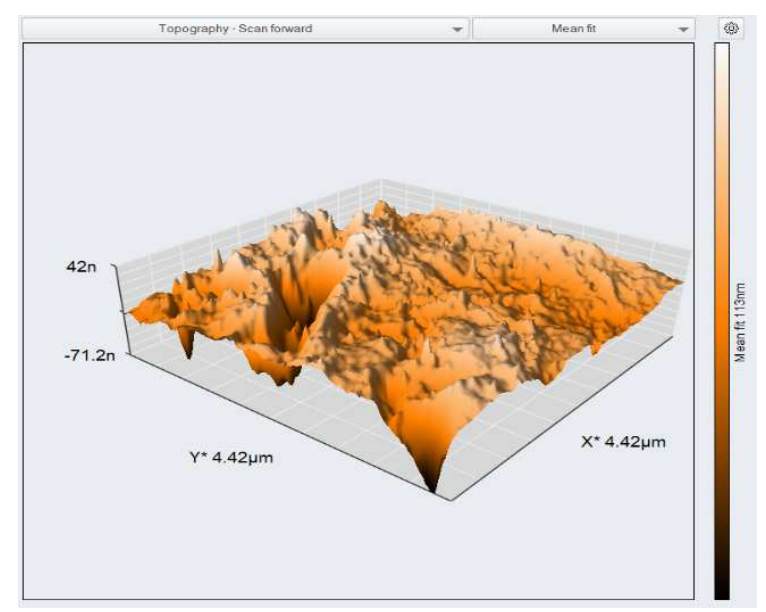

(a)

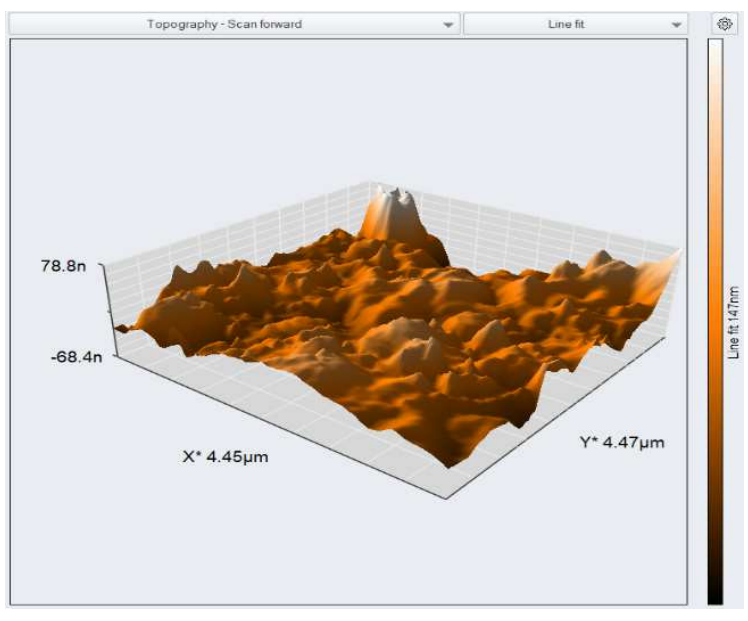

(b) 


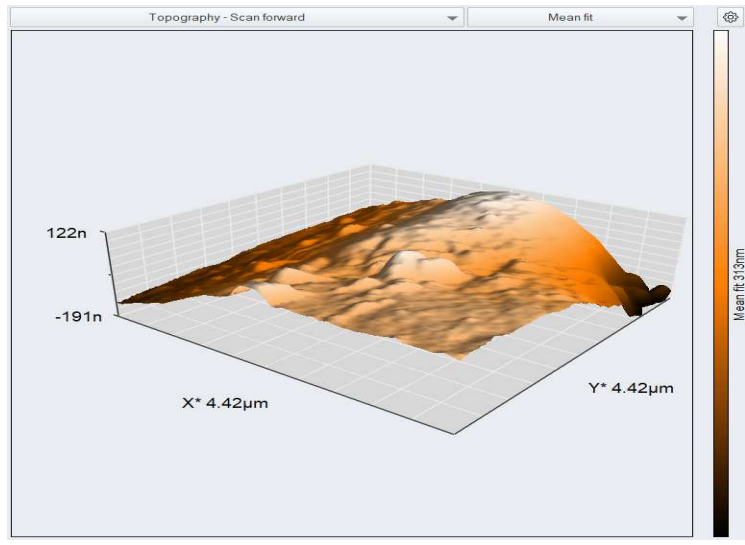

(c)

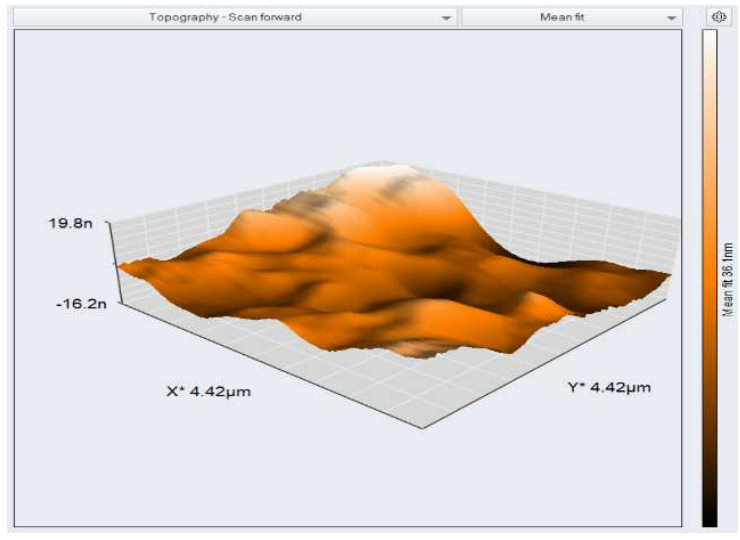

(e)

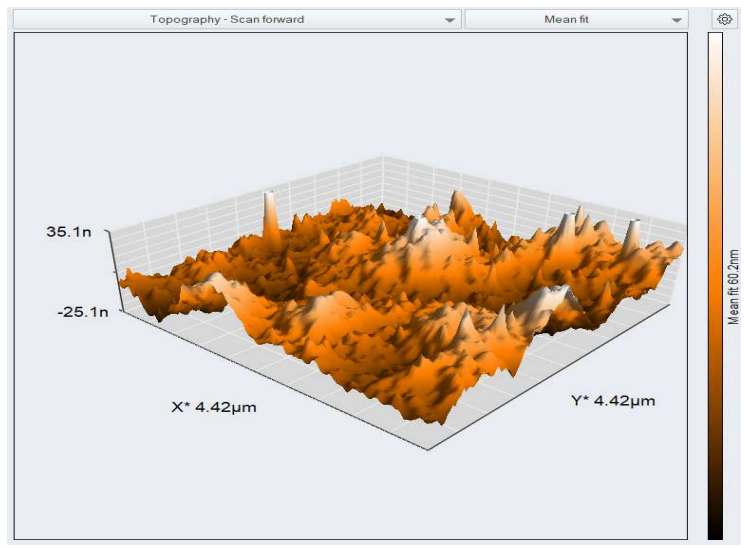

(d)

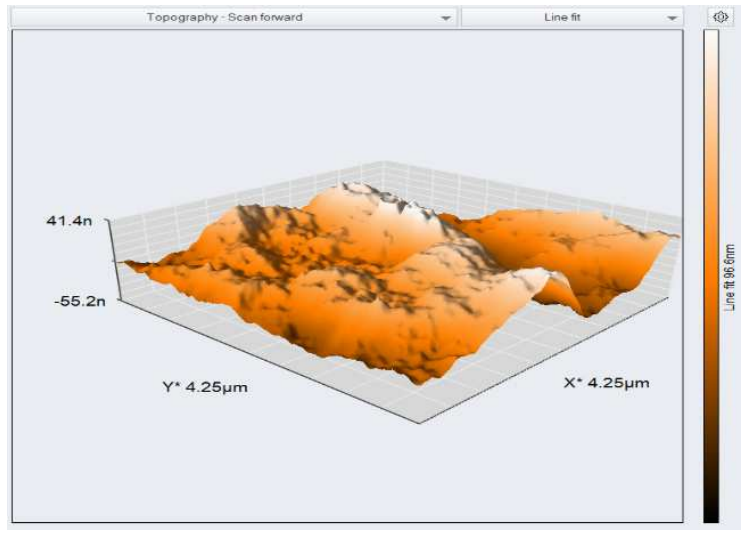

(f)

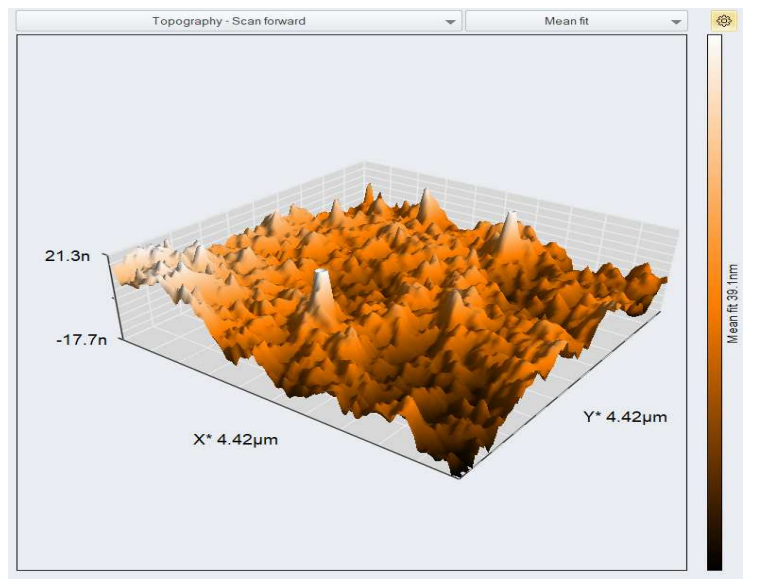

(g)

Fig.5. AFM images of (a) $\mathrm{M}_{1}$ bare membrane, (b) $\mathrm{M}_{2} 0.1 \mathrm{wt} \% \mathrm{CNC}$, (c) $\mathrm{M}_{3} 0.5 \mathrm{wt} \% \mathrm{CNC}$, (d) $\mathrm{M}_{4}$ $1 \mathrm{wt} \% \mathrm{CNC}$, (e) M5: 0.1wt \% CNC-Ser, (f) M6: $0.5 \mathrm{wt} \%$ CNC-Ser, (g) M7: 1wt\% CNC-Ser 
Table 3. The surface roughness of the unmodified and modified membrane.

\begin{tabular}{cccc}
\hline Membrane & $\mathbf{S}_{\mathbf{a}}(\mathbf{n m})$ & $\mathbf{S}_{\mathbf{q}}(\mathbf{n m})$ & $\mathbf{S}_{\mathbf{z}}(\mathbf{n m})$ \\
\hline M1 & 18.13 & 22.63 & 104.57 \\
M2 & 9.48 & 10.72 & 22.26 \\
M3 & 2.99 & 3.83 & 24.70 \\
M4 & 5.64 & 5.99 & 8.42 \\
M5 & 2.42 & 2.97 & 6.58 \\
M6 & 2.69 & 3.19 & 13.65 \\
M7 & 2.42 & 3.26 & 13.68 \\
\hline
\end{tabular}

288

289 3.4. Fouling behavior

290 Fouling behavior was evaluated by applying milk powder solution with concentration of $1000 \mathrm{mg} / \mathrm{l}$

291 as foulant solution. In this mean, three frequent steps were assessed including: distillated water-

292 milk powder solution- distillated water. Fig. 6 illustrated the flux data over each step for all the

293 membranes. The trends of changing flux for all membranes are similar, however, antifouling

294 abilities and flux recoveries are different. From the Fig. the lowest flux for all three steps was

295 observed for the bare membrane (M1) because of low porosity (47.45\%, Table 2) and the

296 hydrophobicity feature of bare PES membrane (WCA of $78.65^{\circ}$ ). In general, all the modified

297 membranes showed better performance rather than the bare PES membrane, verifying the presence

298 of hydrophilic additive. The highest flux over all three steps was obtained for M5 which based on

299 Table 2 showed the lowest WCA and the highest porosity. The higher hydrophilicity of M5 enable

300 the membrane to reject the foulant, provide satisfied flux, improve antifouling behavior and flux

301 recovery. It should be noted that the higher performance of M5 is due to the presence of serine

302 with polar functional groups [40]. 


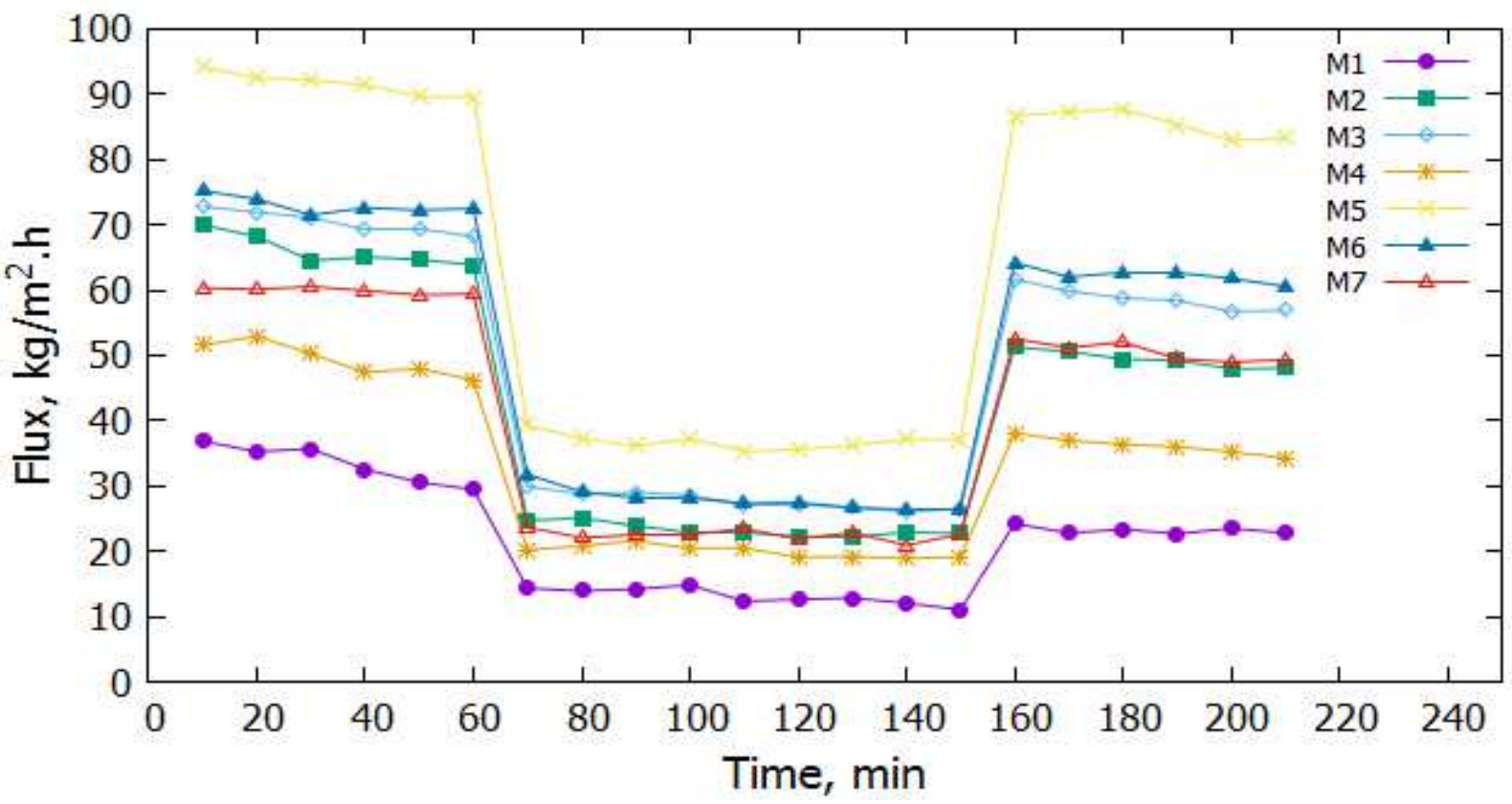

303

304

305

306

307

308

309

310

311

312

Fig.6. Three frequent step experiment: (i) distilled water, (ii) 1000 ppm milk powder solution, and (iii) distilled water filtration.

Also, as zeta potential is an effective criterion for membrane performance in rejecting foulants and flux recovery, the surface charge of the bare membrane (M1) and the optimum membrane for each series (M3 for CNC series and M5 for modified $\mathrm{CNC}$ ) at $\mathrm{pH}$ range of 4-8 was measured and presented in Fig.7. According to the Fig. all mentioned membrane displayed negative values of zeta potential (from -6.66 to $-25.29 \mathrm{mV}$ ) and also an increase in PH value from 3 to 9 caused an increase in negative zeta potential (from -6.66 to -16.33 for M1, from -9.4 to -22.74 for M3, from -12.8 to -25.29 for M5). In each studied $\mathrm{pH}$ value, M5 exhibited the maximum surface negative charge compared to other membranes. It can be concluded that the negative charge density of $\mathrm{CNC}-\mathrm{Ser}$ is improved by $-\mathrm{COOH}$ and $-\mathrm{NH}_{2}$ functionalities on the top-layer rather than $\mathrm{CNC}$, causing a high negative charge on the surface of M5. In point of fact, the results of surface zeta potential are in consist with the results of WCA presented in Table 2 and also is a good justification for obtaining the highest antifouling ability and flux recovery for M5 (Fig.6) [41]. 


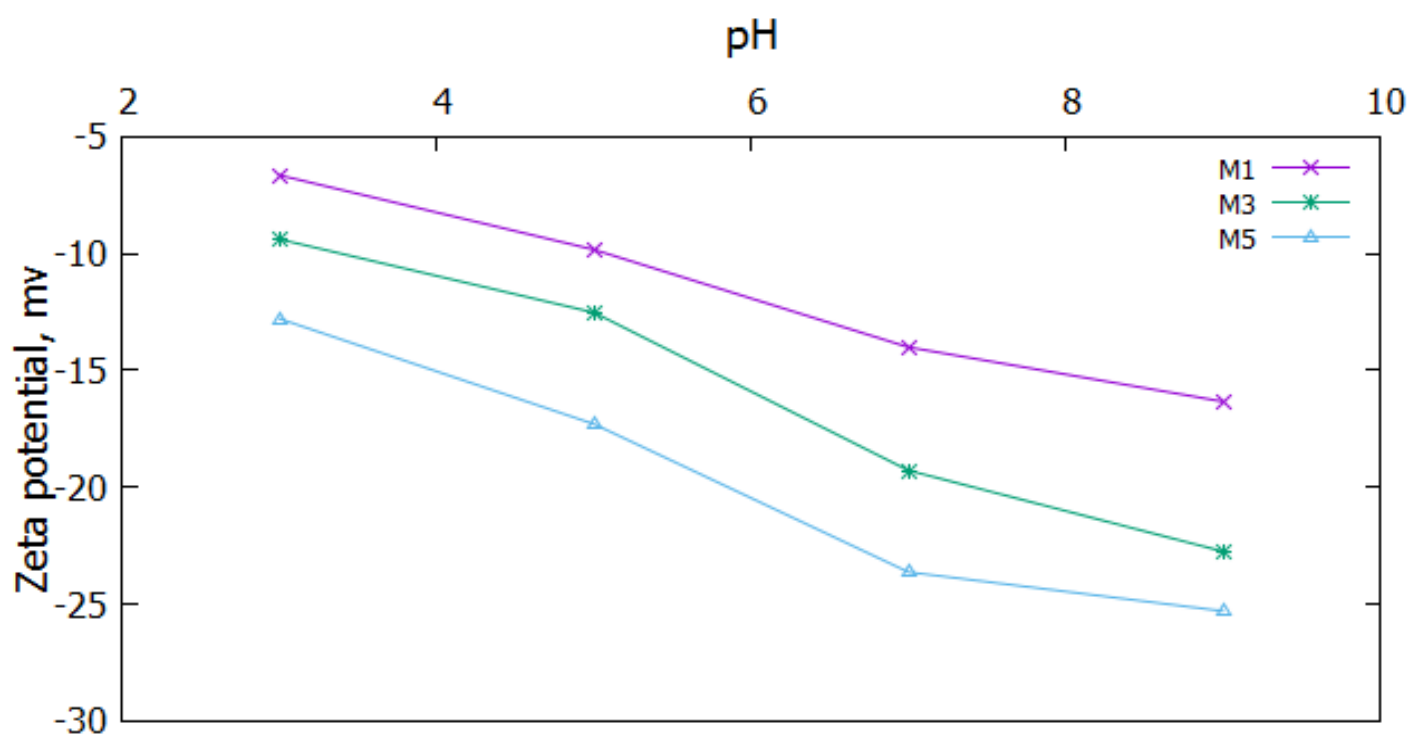

Fig.7. Surface zeta potential of membranes M1, M3, and M5.

319

320

321

322

323

324

325

326

327

328

329

330

Flux recovery ratio (FRR) is a decent criterion to evaluate the performance of the prepared membranes besides PWF. Therefore, FRR was calculated for different prepared membranes and presented in Fig. 8 (with milk powder solution as foulant). From the Fig. the lowest FRR was reported as $69.54 \%$ for the bare membrane, whereas, the membranes embedded with $\mathrm{CNC}$ and CNC-Ser showed an improvement in FRR. The highest values of FRR were achieved for M3 and M5. This result could be explained by surface zeta potential so that based on Fig. 7, M3 and M5 represented more negative surface charge, inhibiting cake layer formation. As a fact, at low loading additives the viscosity of the casting solution is low led to a fast migration of the additives over phase inversion, resulting more hydrophilicity, more surface free energy (Table 2), and more negative charge on the membrane surface. Moreover, FRR was reported as $93.41 \%$ and $83.34 \%$ for M5 and M3, respectively. The better performance of M5 could be explained by hydrogen bonding between- $\mathrm{COOH}$ and $\mathrm{NH}_{2}$ groups of the modified $\mathrm{CNC}$ and $\mathrm{H}_{2} \mathrm{O}$ molecules led to an increased membrane capability against cake layer formation on the membrane surface.

A reduced trend in FRR could be observed with increasing additive loadings, particularly for the unmodified $\mathrm{CNC}$ as a result of unpleasant dispersion and agglomeration in the membrane matrix. This reduction also could be related to surface roughness so that the higher surface roughness caused more foulant cake layer formation on the membrane surface. From Table 4 and 
supplementary data 3, the surface of M3 and M5 was smoother rather than other membranes which is consistent with FRR results. Fouling took place for other membranes with higher surface roughness intensively, resulting lower FRR.

Moreover, in order to present more analysis about fouling phenomenon reversible and irreversible fouling (milk powder solution as foulant) were calculate for each membrane and presented in Fig. 8. From the Fig. the higher reversible fouling which is temporary and the lower irreversible fouling known as permanent fouling were obtained for the membranes embedded with CNC-Ser compared to the membranes with $\mathrm{CNC}$. This outcome verified the better performance of CNC-Ser for improving the fouling characteristics of the bare membrane. As can be seen from the Fig., the bare membrane has the most irreversible fouling which caused a weak performance for applying it during several frequent filtrations. On the other hand, as observed in the Fig. over optimum loading of additives the reversible fouling of the bare membrane increased from 30.22 to $43.67 \%$ and $53.22 \%$ for M3 and M5, respectively, while the irreversible fouling decreased notably from 30.45 to $16.65 \%$ and $6.58 \%$ for M3 and M5, respectively [30, 42].

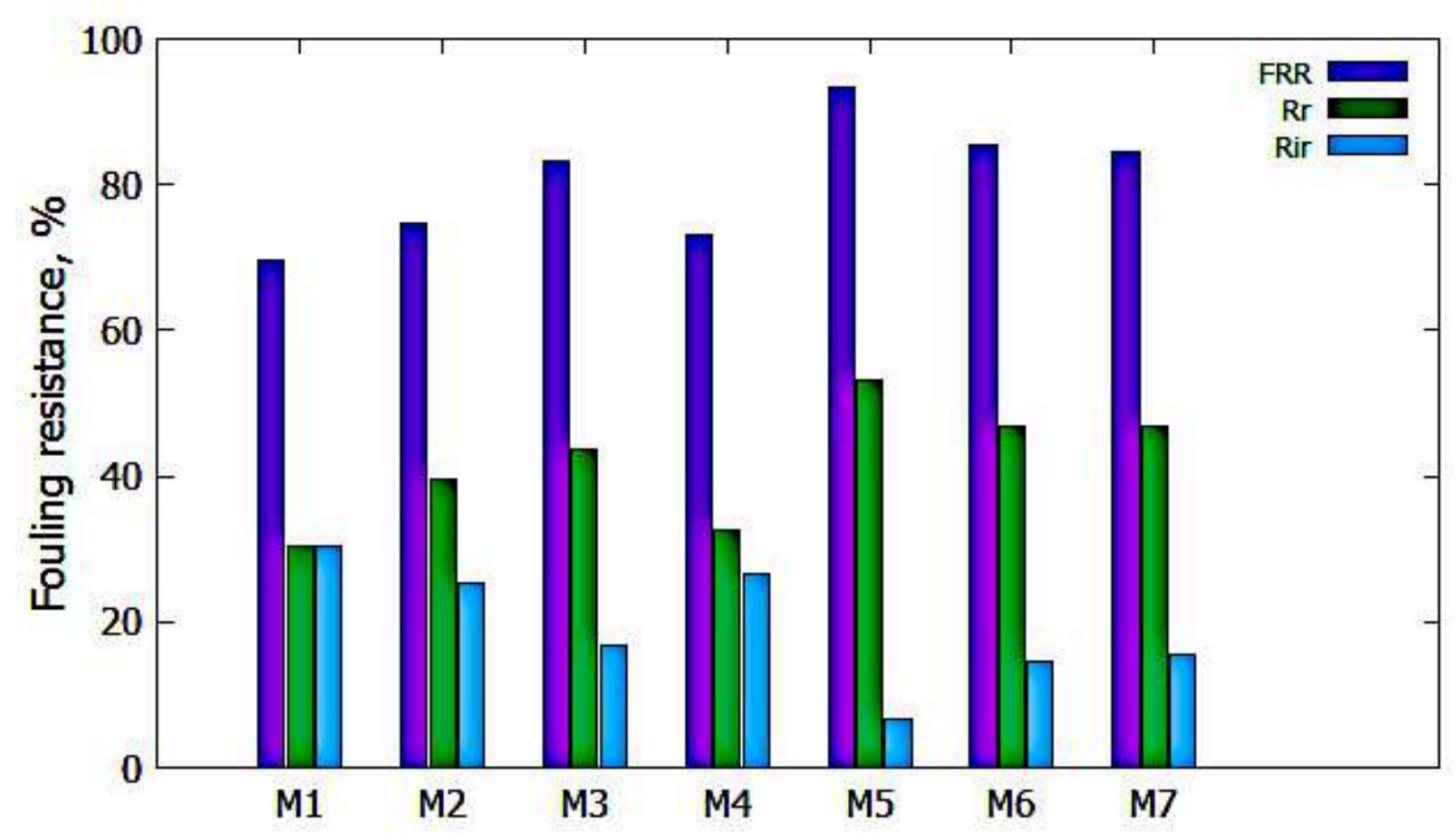

Fig.8. FRR, reversible (Rr) and irreversible (Rir) fouling resistance results of the fabricated membranes. 


\subsection{Oil water removal}

356 In this section, the performance of the prepared membranes in terms of oil rejection was 357 investigated. In this mean three different feed concentrations (100, 300, 500 ppm oil) were 358 examined for all membranes which the results are presented in Table 4. From the data of Table 4, 359 the least FRR and flux values were reported for the bare membrane resulted from its high 360 roughness, low antifouling ability, low porosity and its hydrophobic nature. The membrane 361 embedded with CNC-Ser (modified additive) showed better performance in terms of flux and FRR 362 compared to the membranes embedded with $\mathrm{CNC}$ in a good agreement with the data presented in 363 Fig 5. Further improvement in the FRR and flux of the membranes with CNC-Ser, can be related 364 to the presence of $-\mathrm{COOH}$ and $-\mathrm{NH}_{2}$ groups in serine (M5) led to more surface charge, 365 hydrophilicity, and less surface roughness. Besides, the performance of the prepared membranes 366 for oil removal was assessed by COD removal as presented in Table 4. From COD removal results, 367 the least efficiency for COD removal was reported for the bare membrane (M1) in all three levels 368 of oil concentration. Similar to FRR and Flux data, the rejection performance of membranes 369 embedded with CNC-Ser was higher rather than membranes modified with CNC in all three levels 370 of oil concentration. The maximum COD removal was reported as 99\% for M5 even for the least 371 oil concentration (100 pm), indicating that M5 could be suggested to apply over the long-term 372 filtration of oily wastewaters to provide a nearly stable high rejection and PWF [33].

Table 4. The oil separation results of the bare and modified in different oil concentrations.

\begin{tabular}{|c|c|c|c|c|c|c|c|c|c|}
\hline & \multicolumn{3}{|c|}{ Flux, $\mathrm{kg} / \mathrm{m}^{2} \cdot \mathrm{h}$} & \multicolumn{3}{|c|}{ FRR, \% } & \multicolumn{3}{|c|}{ COD removal, $\%$} \\
\hline & $\begin{array}{c}100 \\
\text { ppm }\end{array}$ & $\begin{array}{l}300 \\
\mathrm{ppm}\end{array}$ & $\begin{array}{l}500 \\
\text { ppm }\end{array}$ & $\begin{array}{l}100 \\
\mathrm{ppm}\end{array}$ & $\begin{array}{l}300 \\
\mathrm{ppm}\end{array}$ & $\begin{array}{l}500 \\
\text { ppm }\end{array}$ & $\begin{array}{l}100 \\
\text { ppm }\end{array}$ & $\begin{array}{l}300 \\
\mathrm{ppm}\end{array}$ & $500 \mathrm{ppm}$ \\
\hline M1 & 17.05 & 20.46 & 21.49 & 74.32 & 76.36 & 75.87 & 58 & 65 & 72 \\
\hline M2 & 30.19 & 34.72 & 36.46 & $77 . .83$ & 77.36 & 77.9 & 78 & 77 & 78 \\
\hline M3 & 36.03 & 41.44 & 45.17 & 88.34 & 89.89 & 90.24 & 90 & 90 & 93 \\
\hline M4 & 25.97 & 31.16 & 33.97 & 78.18 & 78.65 & 77.25 & 92 & 94 & 94 \\
\hline M5 & 47.82 & 58.34 & 62.76 & 98.41 & 98.99 & 99.2 & 99 & 99 & 99 \\
\hline M6 & 36.33 & 44.32 & 48.76 & 94.31 & 92.25 & 93.74 & 98 & 99 & 99 \\
\hline M7 & 29.19 & 35.03 & 38.54 & 92.41 & 91.89 & 90.32 & 97 & 97 & 98 \\
\hline
\end{tabular}


373 Moreover, in order to have a good comparison with the literature some reported data was presented

374 in Table 5. From Table 5, the rejection efficiency of the present research is similar to other studies,

375 whereas, the amount of PWF and FRR are relatively high rather than the others. It should be

376 noticed that the maximum PWF was $150 \mathrm{Kg} / \mathrm{m}^{2}$.d reported from a study with TEG as an additive.

377 Unlike the high amount of PWF, FRR value was relatively low about $45.3 \%$ for this research. In

378 overall, cellulose nanocrystals - Serine showed a good performance for oil rejection with high

379 PWF and FRR.

Table 5. Comparison of the prepared membranes' performance with other studies.

\begin{tabular}{|c|c|c|c|c|c|c|c|c|}
\hline Polymer & Additive & $\begin{array}{c}\text { Additive } \\
\text { optimal } \\
\text { concentration } \\
(\mathrm{wt} \%) \\
\end{array}$ & $\begin{array}{c}\text { Operating } \\
\text { pressure }\end{array}$ & Feed source & $\begin{array}{c}\text { Rejection } \\
(\%)\end{array}$ & $\begin{array}{c}\mathrm{PWF} \\
\mathrm{Kg} / \mathrm{m}^{2} \cdot \mathrm{d}\end{array}$ & $\begin{array}{c}\text { FRR } \\
\%\end{array}$ & Ref \\
\hline PSF & Zirconia/PEG & 15 & 2 bar & $\begin{array}{l}\text { Synthetic oil/ } \\
80 \mathrm{ppm}\end{array}$ & 99.16 & - & - & [43] \\
\hline PSF & PVP K40 & 5 & $1 \mathrm{bar}$ & $\begin{array}{l}\text { Synthetic oil/ } \\
100 \mathrm{ppm}\end{array}$ & 91 & 72 & - & [44] \\
\hline $\mathrm{PES} / 15 \%$ & $\mathrm{PVP} / \mathrm{HMO}$ & 23.08 & $1 \mathrm{bar}$ & $\begin{array}{l}\text { Synthetic oil/ } \\
100-1000 \mathrm{ppm}\end{array}$ & 99 & 100 & 75 & {$[45]$} \\
\hline $\mathrm{PES} / 15 \%$ & $\begin{array}{c}\text { PVP/HNT- } \\
\text { HFO }\end{array}$ & 23.08 & 1 bar & $\begin{array}{l}\text { Synthetic oil/ } \\
1000 \text { ppm }\end{array}$ & 99.7 & 80 & - & {$[46]$} \\
\hline $\mathrm{PES} / 15 \%$ & TEG & 5 & 1.5 bar & $\begin{array}{l}\text { Synthetic } \\
\text { oil/3000 } \\
\text { ppm }\end{array}$ & 98.41 & 150 & 45.3 & {$[47]$} \\
\hline $\mathrm{PES} / 18 \%$ & CuBTC & 0.5 & 3 bar & $\begin{array}{l}\text { Synthetic } \\
\text { oil/4000 } \\
\text { ppm }\end{array}$ & 99 & 29.6 & 81 & {$[30]$} \\
\hline$/ \mathrm{PES} / 17 \%$ & UiO-66 & 0.5 & 3 bar & $\begin{array}{c}\text { Synthetic } \\
\text { oil/100-500 } \\
\text { ppm }\end{array}$ & 99 & 70 & 95.22 & {$[38]$} \\
\hline $\mathrm{PES} / 17 \%$ & FSM-16 & 0.1 & 3 bar & $\begin{array}{c}\text { Synthetic } \\
\text { oil/100-500 } \\
\text { ppm }\end{array}$ & 99 & 61.95 & 99 & [31] \\
\hline PES/18\% & $\begin{array}{c}\text { cellulose } \\
\text { nanocrystals }\end{array}$ & 0.1 & 3 bar & $\begin{array}{c}\text { Real polymer } \\
\text { petrochemical } \\
\text { wastewater } \\
\text { oil/100-500 } \\
\text { ppm }\end{array}$ & 99 & 105 & 99.2 & $\begin{array}{l}\text { This } \\
\text { study }\end{array}$ \\
\hline
\end{tabular}




\subsection{Long-term performance}

383

384

385

386

387

388

389

390

391

392

393

394

395

396

397

398

399

400

401

402

403

404

405

406

407

408

409

410

411

In this section, the long-term performance of the bare membrane, M3 and M5 for oil removal from

Kermanshah polymer production plant wastewater in a dead-end set-up and a cross-flow set-up was investigated.

\subsubsection{Dead-end set-up:}

Flux data for long- term filtration of distillated water and Kermanshah polymer production plant wastewater alternately for M1 (bare membrane), M3 (optimal modified membrane with CNC), and M5 (optimal modified membrane with CNC CNC-Ser) was presented in Fig.9a for $1100 \mathrm{~min}$. It is obvious from the Fig. that the performance of the bare membrane is not satisfied and it could not be a proper case for long term performance as blocking took place for M1 after nearly three cycles. The main reason for this soon blocking of M1 is the hydrophobic nature of the bare PES membrane which adsorb oily components led to the formation of cake layer. Another reason is related to high surface roughness, causing trapping foulant agents. For modified membranes, seven cycles of distilled water were examined, and almost repeatable data were achieved. A gentle decreasing trend in water flux was observed for modified membranes particularly M5. The better performance of M5 is relate to the presence serine, offering more negative charge, antifouling ability, and permeation flux.

\subsubsection{Cross-flow set-up:}

Polymer production plant wastewater was passed through a cross-flow set-up for 600 min to evaluate the performance of M1, M3 and M5 and the flux data were presented in Fig.9b. Also, to evaluate flux recovery of the membranes after $600 \mathrm{~min}$ filtration of polymer production plant wastewater, distillated water was passed through set-up. It should be mentioned that oil was rejected over $97 \%$ for all three membranes, while, M1 presented the least water flux around 10 $\mathrm{kg} / \mathrm{m}^{2} . \mathrm{h}$ similar to dead-end setup, proving the inability of the bare ultrafiltration membrane to get stable oil rejection. Water flux for M3 and M5 was nearly stable around 40 and $85 \mathrm{~kg} / \mathrm{m}^{2} . \mathrm{h}$, respectively. As M5 showed the highest water flux with acceptable stability and the highest flux recovery after $600 \mathrm{~min}$, it could be suggested as a qualified ultrafiltration membrane to get a high stable rejection and water flux for treating Kermanshah polymer production plant wastewater. 


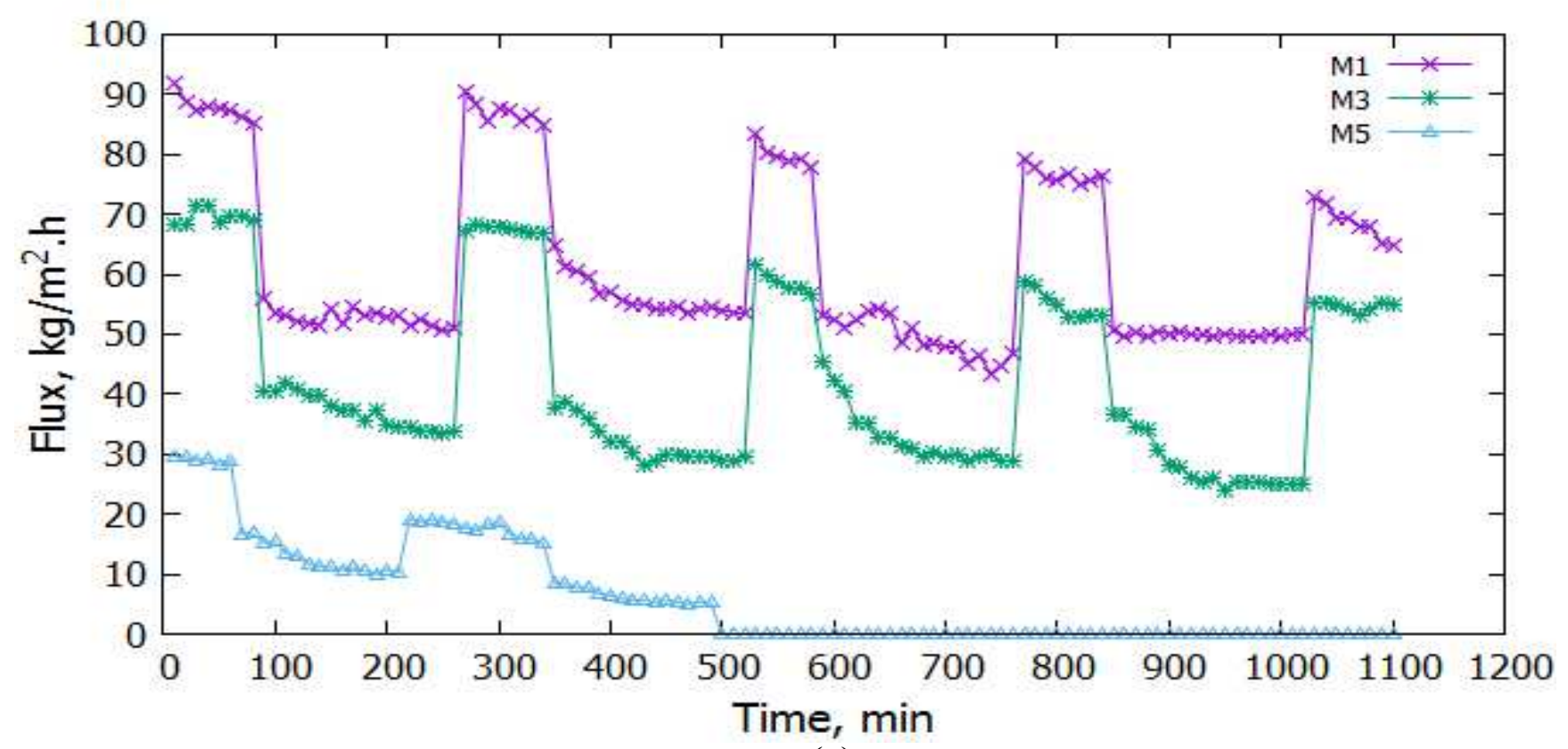

(a)

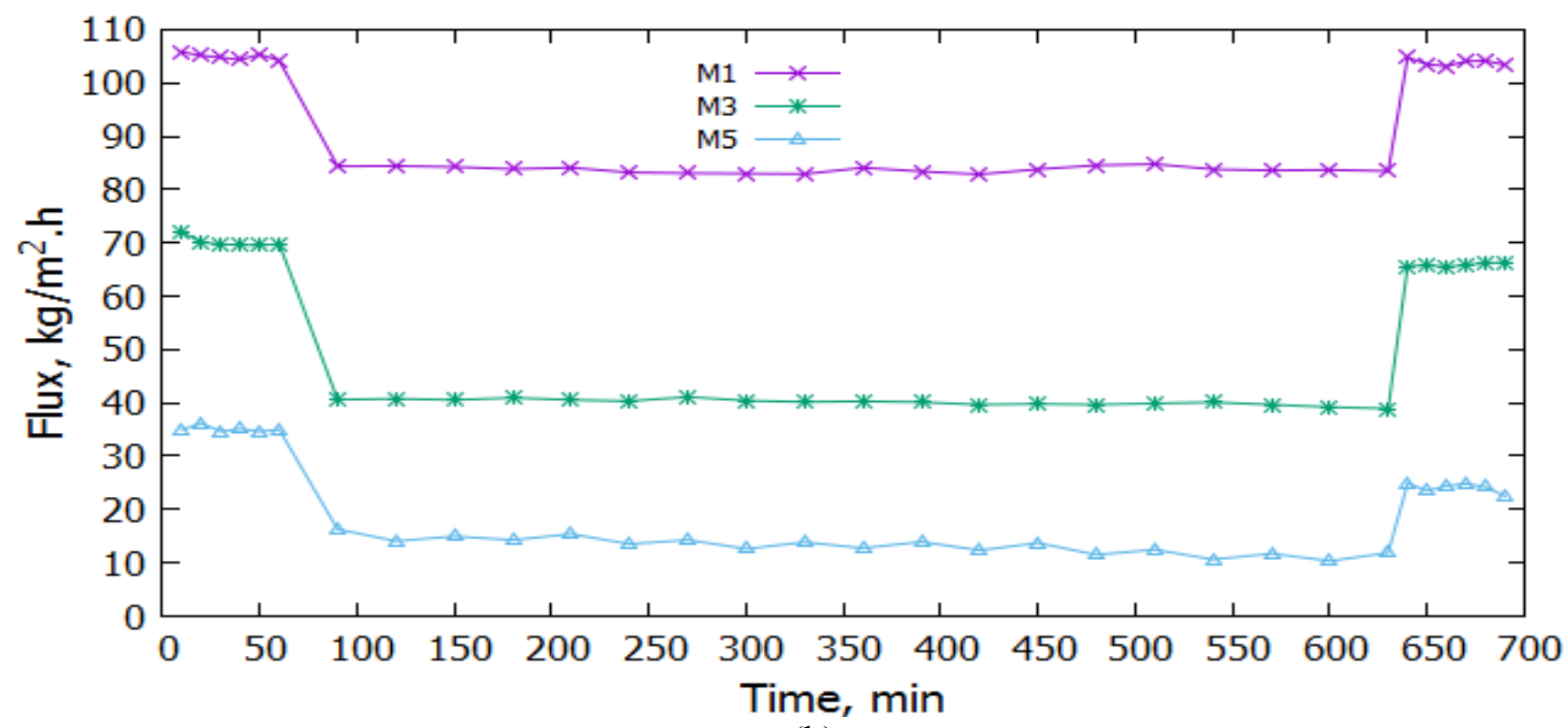

(b)

Fig. 9. Long-term filtration for unmodified and optimal modified membranes in dead-end (a) and cross-flow (b) setup 


\section{Conclusion}

415

416

In this study, water flux and antifouling characteristics of PES ultrafiltration membrane were improved with blending CNC and modified CNC with Serine amino acid (CNC-Ser). The presence $\mathrm{CNC}$ and CNC-Ser progressed the hydrophilicity, porosity, negative surface potential, water flux, and flux recovery ratio of the bare PES ultrafiltration membrane. However, CNC-Ser with $\mathrm{COOH}$ and $-\mathrm{NH}_{2}$ functional groups demonstrated more significant effect on the membrane properties and oil removal performance. The optimally modified membrane $(0.1 \mathrm{wt} \%$ of CNC-Ser $)$ showed the least WCA $\left(41.37^{\circ}\right)$, the highest PWF $\left(91.56 \mathrm{~kg} / \mathrm{m}^{2} . \mathrm{h}\right)$ and FRR $(93.41 \%)$, and great long-term filtration performance in both dead-end (1100 min) and cross-flow set-up (600min).

\section{Declarations:}

- Ethics approval and consent to participate: Not applicable

- Consent for publication: The participant has consented to the submission of the case report to the journal.

- Availability of data and materials: All data generated or analysed during this study are included in this published article

- Competing interests: The authors declare that they have no competing interests

- Funding: Not applicable

- Authors' contributions:

All authors contributed to the study conception and design. Material preparation, data collection and analysis were performed by Foad Gholami and Azar Asadi. The first draft of the manuscript was written by Foad Gholami and all authors commented on previous versions of the manuscript. All authors read and approved the final manuscript.

- Acknowledgements:

The authors would like to acknowledge the central lab of Razi University for the support provided for this research work.

\section{References}

[1] C. Guan, Z. Li, L. Zhu, D. Xia, A superhydrophilic and high demulsification aramid nanofibers membrane with novel poly-pseudorotaxane structure for oil-in-water separation, Separation and Purification Technology, 269 (2021) 118715.

[2] S. Huang, R.H. Ras, X. Tian, Antifouling membranes for oily wastewater treatment: Interplay between wetting and membrane fouling, Current opinion in colloid \& interface science, 36 (2018) 90-109.

[3] M. Li, X. Gao, X. Wang, S. Chen, J. Yu, Wettable and Flexible Silica Nanofiber/Bead-Based Membranes for Separation of Oily Wastewater, ACS Applied Nano Materials, 4 (2021) 2952-2962. 
[4] R. Elshorafa, J. Saththasivam, Z. Liu, S. Ahzi, Efficient oil/saltwater separation using a highly permeable and fouling-resistant all-inorganic nanocomposite membrane, Environmental Science and Pollution Research, (2020) 1-10.

[5] M.A. Santos, F. Capponi, C.H. Ataíde, M.A. Barrozo, Wastewater treatment using DAF for process water reuse in apatite flotation, Journal of Cleaner Production, 308 (2021) 127285.

[6] A. Sadatshojaie, D.A. Wood, S.M. Jokar, M.R. Rahimpour, Applying ultrasonic fields to separate water contained in medium-gravity crude oil emulsions and determining crude oil adhesion coefficients, Ultrasonics Sonochemistry, 70 (2021) 105303.

[7] C.T.N. Mai, N.V. Linh, N.Q. Lich, H.P. Ha, D. Van Quyen, D.Y.Y. Tang, P.L. Show, Advanced materials for immobilization of purple phototrophic bacteria in bioremediation of oil-polluted wastewater, Chemosphere, 278 (2021) 130464.

[8] A.L. Garcia-Costa, A. Luengo, J.A. Zazo, J.A. Casas, Cutting oil-water emulsion wastewater treatment by microwave assisted catalytic wet peroxide oxidation, Separation and Purification Technology, 257 (2021) 117940.

[9] B. Singh, S. Singh, P. Kumar, In-depth analyses of kinetics, thermodynamics and solid reaction mechanism for pyrolysis of hazardous petroleum sludge based on isoconversional models for its energy potential, Process Safety and Environmental Protection, 146 (2021) 85-94.

[10] L. Yan, G. Zhang, L. Zhang, W. Zhang, J. Gu, Y. Huang, J. Zhang, T. Chen, Robust construction of underwater superoleophobic CNTs/nanoparticles multifunctional hybrid membranes via interception effect for oily wastewater purification, Journal of membrane science, 569 (2019) 32-40.

[11] X. Wang, C. Xiao, H. Liu, M. Chen, H. Xu, W. Luo, F. Zhang, Robust functionalization of underwater superoleophobic PVDF-HFP tubular nanofiber membranes and applications for continuous dye degradation and oil/water separation, Journal of Membrane Science, 596 (2020) 117583.

[12] M.A.B. Pauzan, M. Abd Rahman, M.H.D. Othman, Hydrocarbon Separation and Removal Using Membranes, in: Membrane Technology Enhancement for Environmental Protection and Sustainable Industrial Growth, Springer, 2021, pp. 73-90.

[13] M. Kamali, M.E. Costa, T.M. Aminabhavi, I. Capela, Sustainability of treatment technologies for industrial biowastes effluents, Chemical Engineering Journal, 370 (2019) 1511-1521.

[14] A. Yusuf, A. Sodiq, A. Giwa, J. Eke, O. Pikuda, G. De Luca, J.L. Di Salvo, S. Chakraborty, A review of emerging trends in membrane science and technology for sustainable water treatment, Journal of Cleaner Production, (2020) 121867.

[15] C.G. Eggensperger, M. Giagnorio, M.C. Holland, K.M. Dobosz, J.D. Schiffman, A. Tiraferri, K.R. Zodrow, Sustainable Living Filtration Membranes, Environmental science \& technology letters, 7 (2020) 213-218.

[16] Y.-X. Wang, Y.-J. Li, H. Yang, Z.-L. Xu, Super-wetting, photoactive TiO2 coating on amino-silane modified PAN nanofiber membranes for high efficient oil-water emulsion separation application, Journal of Membrane Science, 580 (2019) 40-48.

[17] W. Wang, L. Zhu, B. Shan, C. Xie, C. Liu, F. Cui, G. Li, Preparation and characterization of SLS-CNT/PES ultrafiltration membrane with antifouling and antibacterial properties, Journal of Membrane Science, 548 (2018) 459-469.

[18] H. Fan, J. Gu, H. Meng, A. Knebel, J. Caro, High-flux imine-linked covalent organic framework COFLZU1 membranes on tubular alumina supports for highly selective dye separation by nanofiltration, Angew. Chem., Int. Ed, 57 (2018) 4083-4087.

[19] H. Liu, H. Yu, X. Yuan, W. Ding, Y. Li, J. Wang, Amino-functionalized mesoporous PVA/SiO2 hybrids coated membrane for simultaneous removal of oils and water-soluble contaminants from emulsion, Chemical Engineering Journal, 374 (2019) 1394-1402.

[20] Y. Shi, J. Huang, G. Zeng, W. Cheng, J. Hu, L. Shi, K. Yi, Evaluation of self-cleaning performance of the modified g-C3N4 and GO based PVDF membrane toward oil-in-water separation under visible-light, Chemosphere, 230 (2019) 40-50. 
[21] F. Gholami, S. Zinadini, A. Zinatizadeh, A. Abbasi, TMU-5 metal-organic frameworks (MOFs) as a novel nanofiller for flux increment and fouling mitigation in PES ultrafiltration membrane, Separation and Purification Technology, 194 (2018) 272-280.

[22] C. Balcik-Canbolat, B. Van der Bruggen, Efficient removal of dyes from aqueous solution: the potential of cellulose nanocrystals to enhance PES nanocomposite membranes, Cellulose, 27 (2020) 5255-5266.

[23] W. Lee, P. Goh, W. Lau, C.S. Ong, A. Ismail, Antifouling zwitterion embedded forward osmosis thin film composite membrane for highly concentrated oily wastewater treatment, Separation and Purification Technology, 214 (2019) 40-50.

[24] S. Zarghami, T. Mohammadi, M. Sadrzadeh, Preparation, characterization and fouling analysis of inair hydrophilic/underwater oleophobic bio-inspired polydopamine coated PES membranes for oily wastewater treatment, Journal of Membrane Science, 582 (2019) 402-413.

[25] J. Saththasivam, Y. Wubulikasimu, O. Ogunbiyi, Z. Liu, Fast and efficient separation of oil/saltwater emulsions with anti-fouling $\mathrm{ZnO}$ microsphere/carbon nanotube membranes, Journal of Water Process Engineering, 32 (2019) 100901.

[26] J. Zhang, F. Zhang, A. Wang, Y. Lu, J. Li, Y. Zhu, J. Jin, Zwitterionic nanofibrous membranes with a superior antifouling property for gravity-driven crude oil-in-water emulsion separation, Langmuir, 35 (2018) 1682-1689.

[27] P. Daraei, N. Ghaemi, H.S. Ghari, An ultra-antifouling polyethersulfone membrane embedded with cellulose nanocrystals for improved dye and salt removal from water, Cellulose, 24 (2017) 915-929.

[28] X. Wang, N. Feng, Z. Shi, N. Zhou, J. Lu, J. Huang, L. Gan, Stimuli-responsive flexible membrane via coassembling sodium alginate into assembly membranes of rod-like cellulose nanocrystals with an achiral array, Carbohydrate Polymers, 262 (2021) 117949.

[29] J.A. Fereiro, G. Porat, T. Bendikov, I. Pecht, M. Sheves, D. Cahen, Protein electronics: chemical modulation of contacts control energy level alignment in gold-azurin-gold junctions, Journal of the American Chemical Society, 140 (2018) 13317-13326.

[30] F. Gholami, S. Zinadini, A.A. Zinatizadeh, Preparation of high performance CuBTC/PES ultrafiltration membrane for oily wastewater separation; A good strategy for advanced separation, Journal of Environmental Chemical Engineering, 8 (2020) 104482.

[31] M. Samari, S. Zinadini, A.A. Zinatizadeh, M. Jafarzadeh, F. Gholami, A new fouling resistance polyethersulfone ultrafiltration membrane embedded by metformin-modified FSM-16: Fabrication, characterization and performance evaluation in emulsified oil-water separation, Journal of Environmental Chemical Engineering, 9 (2021) 105386.

[32] G. Hurwitz, G.R. Guillen, E.M. Hoek, Probing polyamide membrane surface charge, zeta potential, wettability, and hydrophilicity with contact angle measurements, Journal of Membrane Science, 349 (2010) 349-357.

[33] F. Gholami, S. Zinadini, A.A. Zinatizadeh, M. Samari, Preparation and Characterization of Antifouling Mixed Matrix Microfiltration Membranes Modified by Metal-Organic Frameworks for Usage in Membrane Bioreactor (MBR), Environment and Water Engineering, 6 (2020) 122-133.

[34] H. Zangeneh, A.A. Zinatizadeh, S. Zinadini, M. Feyzi, E. Rafiee, D.W. Bahnemann, A novel L-Histidine (C, N) codoped-TiO2-CdS nanocomposite for efficient visible photo-degradation of recalcitrant compounds from wastewater, Journal of hazardous materials, 369 (2019) 384-397.

[35] W. Chen, H. He, H. Zhu, M. Cheng, Y. Li, S. Wang, Thermo-responsive cellulose-based material with switchable wettability for controllable oil/water separation, Polymers, 10 (2018) 592.

[36] A. Azizi, Green Synthesis of Fe 304 Nanoparticles and Its Application in Preparation of Fe 30 4/Cellulose Magnetic Nanocomposite: A Suitable Proposal for Drug Delivery Systems, Journal of Inorganic and Organometallic Polymers and Materials, (2020) 1-10. 

Assembled on Cellulose and SiO2 Substrates via a Layer-by-Layer Approach, Polymers, 13 (2021) 939. [38] M. Samari, S. Zinadini, A.A. Zinatizadeh, M. Jafarzadeh, F. Gholami, Designing of a novel polyethersulfone (PES) ultrafiltration (UF) membrane with thermal stability and high fouling resistance using melamine-modified zirconium-based metal-organic framework (UiO-66-NH2/MOF), Separation and Purification Technology, 251 (2020) 117010. PVDF/PFSA-g-GO ultrafiltration membrane with enhanced permeation and antifouling performances, Separation and Purification Technology, 233 (2020) 116038. properties of cellulose acetate ultrafiltration membrane by incorporation of ZnO@ graphitic carbon nitride nanocomposite, Carbohydrate Polymers, 256 (2021) 117413.

558 [41] V. Hoseinpour, A. Ghaee, V. Vatanpour, N. Ghaemi, Surface modification of PES membrane via aminolysis and immobilization of carboxymethylcellulose and sulphated carboxymethylcellulose for 560 hemodialysis, Carbohydrate polymers, 188 (2018) 37-47.

561 [42] V. Vatanpour, A. Sanadgol, Surface modification of reverse osmosis membranes by grafting of polyamidoamine dendrimer containing graphene oxide nanosheets for desalination improvement, Desalination, 491 (2020) 114442. zirconia/polysulfone composite membrane for treatment of wastewater containing oil, Separation and purification technology, 70 (2009) 153-159. polysulfone membrane, Brazilian Journal of Chemical Engineering, 34 (2017) 583-596. (PES)/hydrous manganese dioxide (HMO) mixed matrix membranes with improved anti-fouling properties for oily wastewater treatment process, RSC Advances, 4 (2014) 17587-17596.

[46] S.N.W. Ikhsan, N. Yusof, F. Aziz, N. Misdan, A.F. Ismail, W.-J. Lau, J. Jaafar, W.N.W. Salleh, N.H.H. Hairom, Efficient separation of oily wastewater using polyethersulfone mixed matrix membrane incorporated with halloysite nanotube-hydrous ferric oxide nanoparticle, Separation and Purification Technology, 199 (2018) 161-169. Innovation, (2021) 101701. 